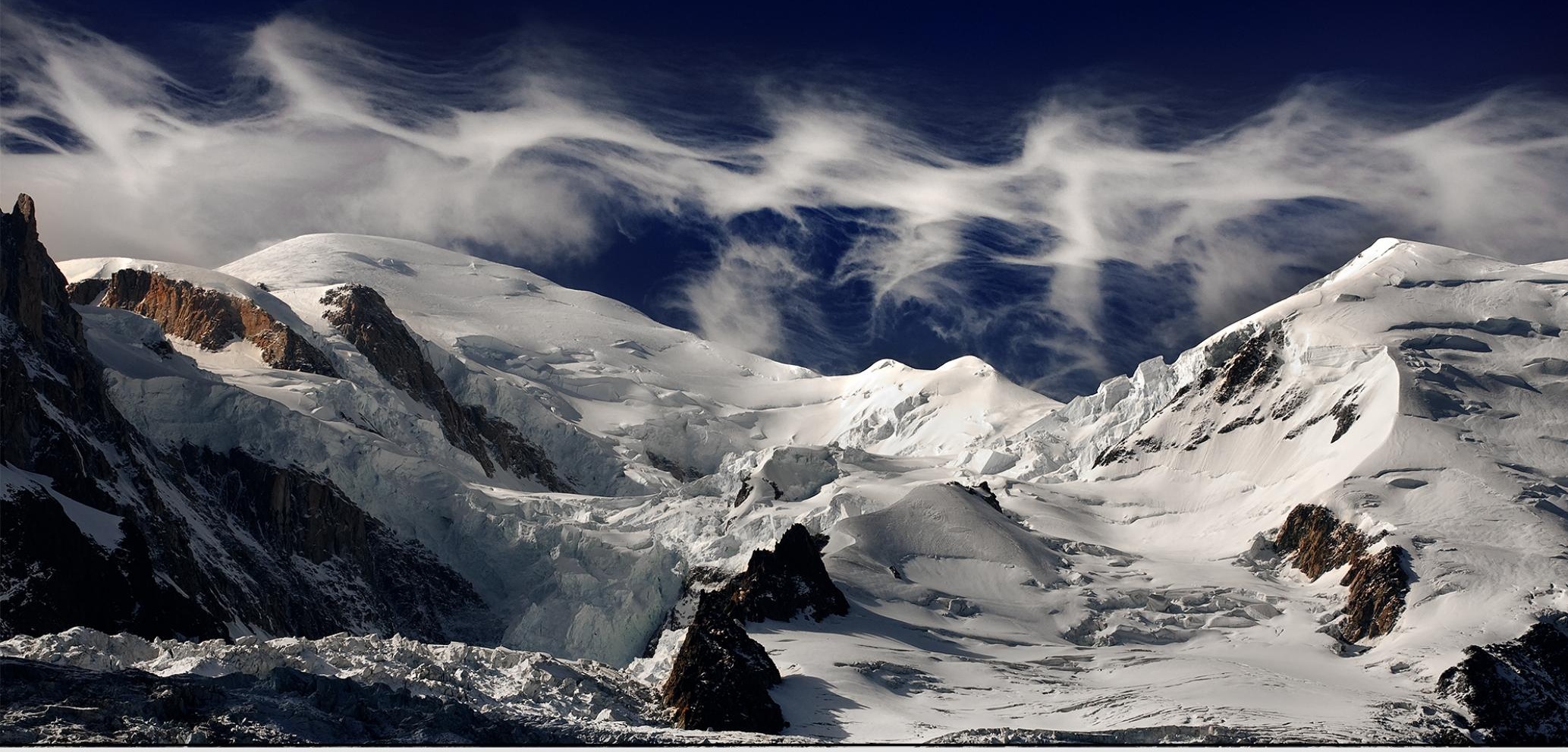

\title{
Predicciones mensual, estacional y anual
}

ASUNCIÓN PASTOR SAAVEDRA

Área de Evaluación y Modelización del Clima (AEMC), Agencia Estatal de Meteorología (AEMET)

ERoteida SÁnchez García y José Voces Aboy

Delegación territorial (DT) Cantabria, AEMET

BEATRIZ NAVAscuÉs FernándeZ-Victorio

Consejero técnico, AEMET

FRANCISCO DOBLAS-REYES

Institució Catalana de Recerca i Estudis Avanats (ICREA), Barcelona Supercomputing Center-Centro Nacional de Supercomputación (BSC)

We are entering a new era in technological innovation and in use and integration of different sources of information for the wellbeing of society. New predictive tools that will detail weather conditions down to neighborhood and street level, and provide early warnings a month ahead, and forecasts from rainfall to energy consumption will be some of the main outcome of the research activities in weather science over the next decade, and a better understanding of small-scale processes and their inherent predictability should go together with a better comprehension of how weather related information influence decisional processes.

Michel JARRAUD, 2015, Secretario general de la World Meteorological Organization (WMO) 2004-2015

Las predicciones a largo plazo proporcionan un abanico de posibles cambios en las condiciones atmosféricas de un cierto mes, estación o año venidero, con respecto a los denominados valores normales. Debido a la naturaleza caótica de la atmósfera, es imposible predecir las variaciones diarias del tiempo en una localidad específica con meses de antelación. Incluso es imposible predecir con exactitud el tiempo promedio en zonas de cierta amplitud. En este capítulo se examinan estos conceptos punto por punto y se describe qué pueden aportar estas predicciones a largo plazo a la sociedad.

Palabras clave: sistemas de predicción por conjuntos aplicados a la predicción de largo plazo, predicción vs proyección, predicción mensual, ensembles de conveniencia, predicción estacional, S-ClimWare, EUROSIP, IRI, predicción anual, predicción interanual. 


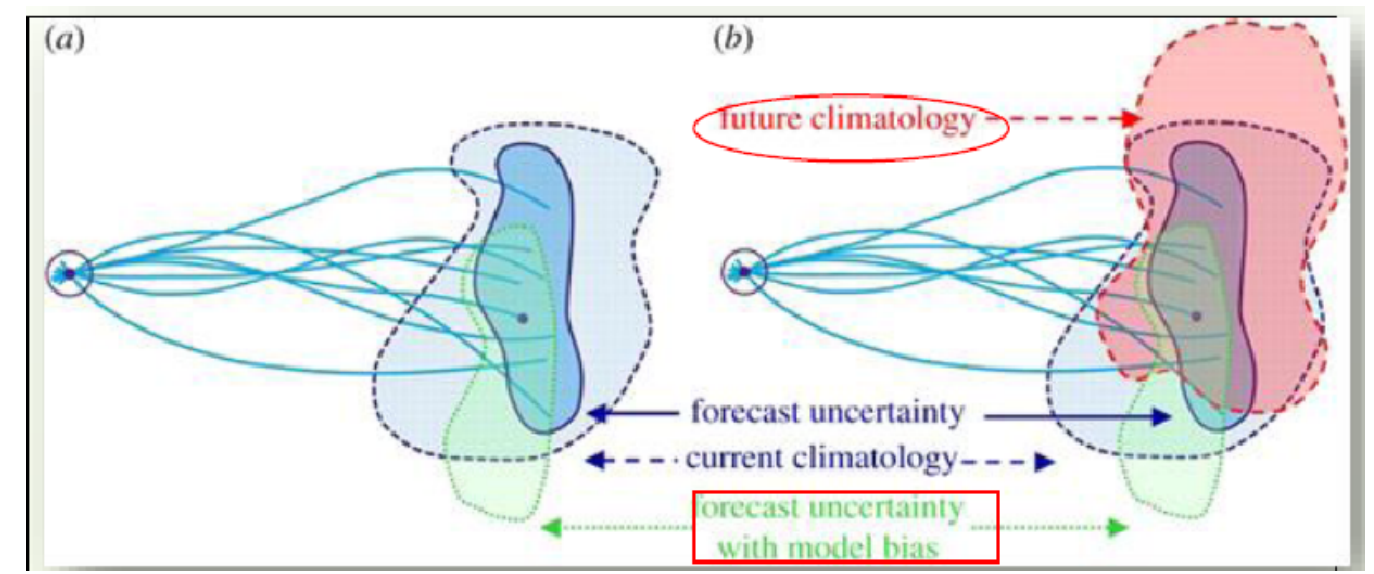

Figura 28.1: Esquema de los sistema(s) de predicción por conjuntos (SPC) con escalas de tiempo desde la estacional hasta decadal, mostrando: a) el impacto de los sesgos del modelo y b) un clima cambiante. La incertidumbre en las predicciones del modelo surge tanto de la incertidumbre de la condición inicial como la incertidumbre del modelo. Adaptada de la Figura 8 de SLINGo y PALMER [68].

\subsection{Predicciones de largo plazo}

Este capítulo está dedicado a las predicciones de largo plazo, predicciones mensuales, predicciones estacionales, predicciones anuales y predicciones decadales. En primer lugar, se ha insistido en las incertidumbres propias del largo plazo y en la diferencia existente entre predicciones y proyecciones climáticas. En segundo lugar, se ha prestado especial atención a la descripción del sistema del European Centre for Medium-range Weather Forecasts -Centro Europeo de Predicción a Plazo Medio- (ECMWF), para la predicción extendida más allá del medio plazo hasta la escala mensual y la predicción de más largo alcance estacional y anual, y a los productos correspondientes a cada escala. Conceptos importantes son la predicción por conjuntos y los denominados sistemas de predicción por conjuntos de conveniencia. Igualmente, se discute que la información sobre la fiabilidad de las predicciones climáticas es crucial para cualquier usuario de información climática de cara a saber la utilidad de esas predicciones para apoyar el proceso de toma de decisiones.

Un punto especial estriba en subrayar las ventajas de considerar las predicciones en las distintas escalas de tiempo en el contexto de la denominada predicción sin costuras (seamless, en inglés), que podría describirse como la apuesta para hacer compatibles las predicciones de los distintos plazos, atendiendo a su concepción de base, su contenido y su formato. Y como siempre, sobrevolando el reto de la debida comunicación de la predicción probabilista a los usuarios de la información procedente de tales ensembles.

\subsubsection{Fundamentos}

Siguiendo las directrices de la Organización Meteorológica Mundial (OMM), se ha venido utilizando la definición de plazos de predicción de 3 a 10 días para definir el medio plazo. La OMM se refiere a la gama de 10 a 30 días como rango o alcance extendido (aunque en el ECMWF se utiliza a menudo el término predicción mensual) y de 30 días a 2 años como a largo plazo. La OMM ha designado al ECMWF como un Centro de Producción Global de las previsiones a largo plazo - uno de los quince existentes en el mundo.

Las predicciones de largo plazo proporcionan información acerca de las condiciones atmosféricas y oceánicas promediadas para los próximos meses (pocos). A pesar de la naturaleza caótica de la atmósfera (ver cap. 5 en la página 49), las predicciones de largo plazo se apoyan en un número de componentes que muestran variaciones en escalas de tiempo largas (estaciones y años) y, hasta cierto punto, son predecibles. La más importante de estas componentes es el ciclo del ENSO (El Niño-Oscilación del Sur, sec. 29.2.1 en la página 484), fenómeno acoplado atmósfera-océano centrado en el Pacífico tropical pero siendo la escala de las fluctuaciones bastante amplia, ya que los cambios en las temperaturas de la superficie del mar (sea surface temperature -temperatura de la superficie marina- (SST)) con frecuencia afectan no solo a la anchura completa del Pacífico, sino también a las otras cuencas oceánicas y los cambios en la lluvia y vientos tropicales cubren una distancia superior a la mitad de la circunferencia de la Tierra. Los episodios El Niño (también denominados episodios cálidos del Pacífico) y los episodios La Niña (conocidos también 
como episodios fríos del Pacífico) representan extremos opuestos del ciclo ENSO. El ciclo ENSO es la mayor fuente conocida de la variabilidad climática interanual. Los cambios en la temperatura de la superficie del mar del Pacífico no son la única causa de los cambios predecibles en los patrones de tiempo. Existen otras causas de variabilidad climática estacional: así, temperaturas inusualmente cálidas o frías de la superficie del mar en el Atlántico tropical o en el océano Índico pueden ocasionar impactos importantes en el clima de las estaciones en los continentes vecinos. Por ejemplo, la temperatura de la superficie del mar en la parte occidental del océano Índico tiene un efecto intenso en la precipitación en el África oriental tropical y las condiciones oceánicas en el Atlántico tropical afectan a la lluvia en el noreste de Brasil. Además de los océanos tropicales, existen otros factores que pueden afectar al clima estacional como son la cubierta de nieve y la humedad del suelo. Cuando la cubierta de nieve está sobre el promedio para una estación y región dada, tiene una mayor influencia refrigerante en el aire que la habitual. La humedad del suelo, cuyo efecto es más intenso durante las estaciones cálidas, ejerce también una influencia refrigerante. Todos esos factores que afectan a la circulación atmosférica constituyen la base de las predicciones a largo plazo. La modelización climática y la predicción estacional han puesto de manifiesto hace ya bastante tiempo cómo las interacciones entre la atmósfera y otros elementos del sistema Tierra introducen nuevas retroalimentaciones en escalas temporales largas, que proporcionan el potencial para la predecibilidad (ver cap. 12 en la página 155) en escalas estacionales y más largas.

A causa de la lentitud del desarrollo y del decaimiento de las anomalías de las SST, los efectos en la atmósfera, en lugares y durante épocas del año en que son notables, son con frecuencia coherentes para un periodo temporal de varios meses. Serían importantes incluso para un tiempo incluso más largo, si no fuera por el hecho de que dependen de forma bastante intensa de la estación del año. Dicho de otra forma, una anomalía de SST dada puede tener un efecto bien definido en el clima en alguna localidad en una cierta época del año, pero a medida que la estación progresa, la misma anomalía de SST puede tener un efecto diferente, o incluso puede que ya no cause ningún efecto.

La falta de predecibilidad de la atmósfera en las escalas extendida y de largo alcance, conlleva una incertidumbre intrínseca a las predicciones estacionales y de mayor horizonte temporal, cuyo origen se comentará posteriormente. Dentro del periodo de predicción, este tipo de predicciones no pronostican de forma determinista eventos de tiempo individuales, sino un conjunto de posibles realizaciones del tiempo atmosférico cuya estadística se puede comparar con las condiciones climáticas características de cada lugar. Así, las predicciones en estos alcances son de naturaleza probabilista, y de esta forma se comunica su incertidumbre.

En el ECMWF, análogamente a los rangos medio y extendido, las predicciones a largo plazo se obtienen con el modelo IFS (Integrated Forecast System) acoplado atmósfera-océano. El modelo se integra para un rango de varios meses; el proceso se repite muchas veces, con ligeras variaciones para representar las incertidumbres en el proceso de predicción, produciendo así un ensemble o SPC (ver cap. 13 en la página 165).

\subsubsection{Incertidumbres propias del largo pla- zo}

LORENZ mostró claramente que la incertidumbre en las condiciones iniciales, pese a ser pequeña, conducirá a la incertidumbre en la predicción tras un cierto periodo de unos cuantos días, variable; dependiendo del estado inicial de la atmósfera. Como consecuencia, la comunidad de predicción numérica empezó a considerar el uso de métodos probabilistas para la predicción, especialmente más allá del límite determinista de una semana o así, sugerido por LORENZ [68]. La implementación temprana de los métodos probabilistas en la predicción numérica del tiempo se basó en la aplicación de perturbaciones aleatorias pequeñas a las variables de estado atmosféricas (temperatura, humedad, vientos y presión) en la condición analizada inicial. Ya que el comportamiento de la atmósfera es no lineal, estas perturbaciones pequeñas son amplificadas por procesos caóticos y cada predicción difiere de las otras. La teoría de LORENZ de la atmósfera (y océano) como un sistema no lineal, caótico impregna todo lo concerniente a la predicción del tiempo y del clima y, como tal, ha influido en el desarrollo de los SPC, probabilistas, en todos los plazos de predicción. Ha mostrado también que las fuentes de incertidumbre no se encuentran limitadas a las condiciones iniciales -las bases del modelo de LORENZ- sino que la incertidumbre del modelo (cap. 17 en la página 257) desempeña un papel crítico en todas las escalas temporales. 


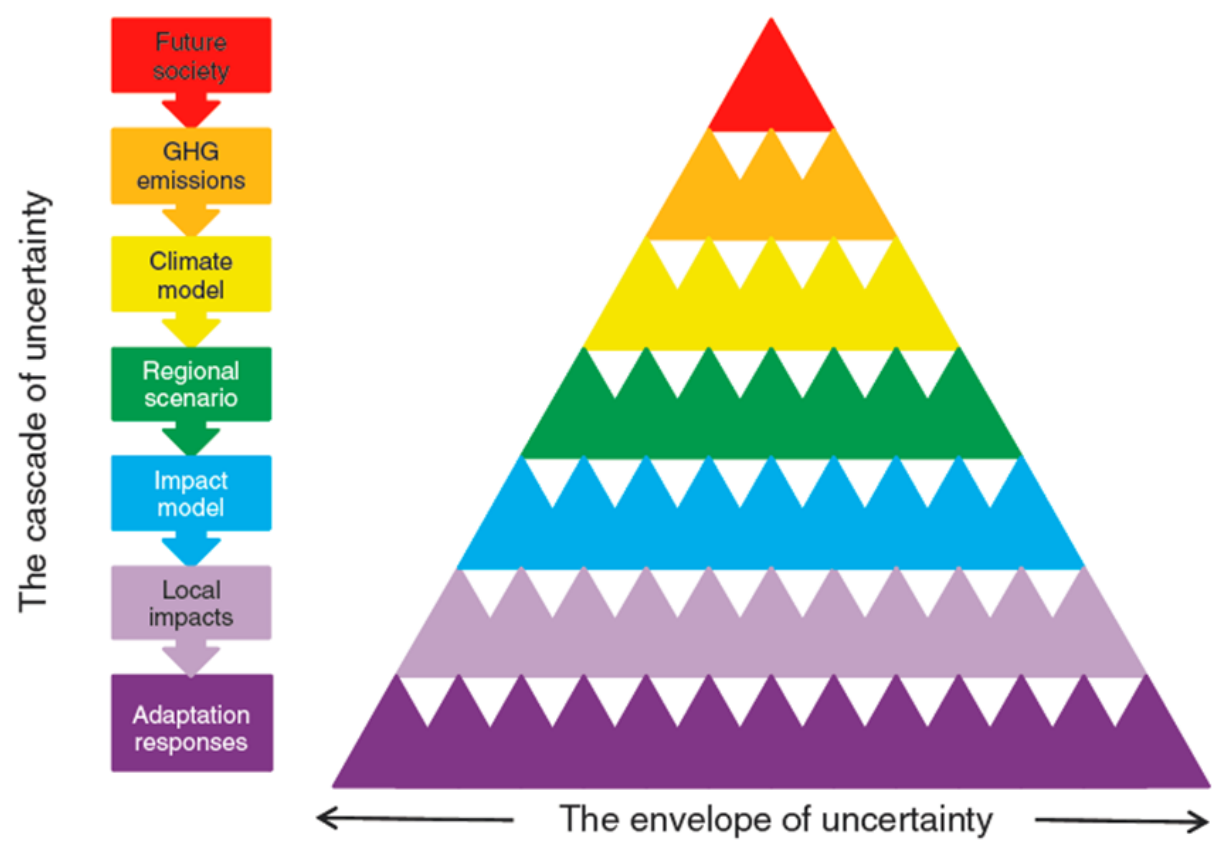

Figura 28.2: La cascada de incertidumbre presentada por WILBY y DESSAI [86], ilustrando el crecimiento de la envolvente de incertidumbre a partir de varias fuentes que van desde la sociedad futura a la respuesta a la adaptación: https: //www. climate-lab-book. ac. uk/2014/cascade-of-uncertainty/, https: //www. researchgate. net/publication/271711914_Climate_change_impacts_and_ adaptation_in_forest_management_a_review/figures? $l_{0}=1$

Es importante, sin embargo, distinguir entre la incertidumbre del modelo que surge del conocimiento imperfecto del sistema real, tal como la representación del ciclo de carbono que es determinante en las escalas temporales más largas, y la incertidumbre procedente de los fenómenos a escala submalla (ver sec. 10.5 en la página 137) que se comprenden bastante bien pero que se representan de forma limitada debido a la resolución del modelo, y que son relevantes en todas las escalas.

En resumen, tanto la descripción de las condiciones iniciales como los procesos que se representan en los modelos de predicción del tiempo o del clima son causa de la incertidumbre de sus pronósticos (Figura 28.1 en la página 448). No obstante, dependiendo de la escala temporal que se predice, unos son más relevantes que otros. Más allá del medio plazo, los errores en las condiciones iniciales atmosféricas son progresivamente menos determinantes y la correcta descripción de las oceánicas deviene esencial, al igual que los errores producidos por la formulación del modelo de circulación general contribuyen más significativamente a la incertidumbre. Las proyecciones de cambio climático presentan algunos retos diferentes de la predicción del tiempo o la predicción estacional. La influencia de las condiciones iniciales oceánicas es pequeña o aproximadamente pequeña al ir más allá de la década e, ignorando las incertidumbres en los escenarios de emisión y en otros factores externos al sistema climático como los forzamientos procedentes de emisiones volcánicas, la principal fuente de incertidumbre procede de la formulación de los modelos, relacionada particularmente con la sensibilidad del sistema climático al forzamiento de gases de efecto invernadero. De otra forma, existen varias fuentes de incertidumbre en el proceso de modelización climática, bien sea en relación con las imperfecciones de los modelos de circulación general, escenarios de emisión de aerosoles $\mathrm{y}$ de gases de efecto invernadero o con la variabilidad natural climática. Estas incertidumbres fueron descritas en forma de cascada por Mitchell y Hulme en 1999 ([55], ilustrado en Figura 28.2).

KJELLSTROM et al. [44] subrayan que las diferentes fuentes de incertidumbre limitan nuestra habilidad para proporcionar respuestas precisas acerca de lo que sucederá con el clima en el futuro. Esto es cierto tanto a nivel global como, incluso más, en un contexto regional o local, lo que no impide dar respuestas con un abanico de incertidumbre estimado. 


\begin{tabular}{|c|c|c|c|}
\hline & $\mathbf{F R}$ & Tendencia del FR & {$\left[\mathrm{CO}_{2}\right]$ en 2100} \\
\hline RCP2.6 & $2,6 \mathrm{~W} / \mathrm{m}^{2}$ & decreciente en $\mathbf{2 1 0 0}$ & $421 \mathrm{ppm}$ \\
\hline RCP4.5 & $4,5 \mathrm{~W} / \mathrm{m}^{2}$ & estable en $\mathbf{2 1 0 0}$ & $538 \mathrm{ppm}$ \\
\hline RCP6.0 & $6,0 \mathrm{~W} / \mathrm{m}^{2}$ & creciente & $670 \mathrm{ppm}$ \\
\hline RCP8.5 & $8,5 \mathrm{~W} / \mathrm{m}^{2}$ & creciente & 936 ppm \\
\hline
\end{tabular}

Figura 28.3: Forzamiento radiativo total (FR), tendencia del FR y concentración de $\mathrm{CO}_{2}$ para las nuevas Sendas Representativas de Concentración (RCP, de sus siglas en inglés) ([5] https: //www. miteco.gob. es/es/ceneam/ recursos/mini-portales-tematicos/guia-resumida-grupo-trabajoi_tcm30-376939. pdf).

\subsubsection{Predicción vs proyección}

El cambio climático es el resultado de desequilibrios en el balance energético de la Tierra, causados por procesos y agentes naturales y antropogénicos. El forzamiento radiativo (FR) cuantifica el cambio en los flujos de energía originados por variaciones en la acción de estos agentes. En el Quinto Informe de Evaluación (AR5, sec. 29.6.2 en la página 514) del IPCC (sec. 29.6.1 en la página 513) se han definido cuatro nuevos escenarios de emisión, las denominadas Sendas Representativas de Concentración (RCP, de sus siglas en inglés). Éstas se identifican por su FR total para el año 2100 que varía desde 2,6 a $8,5 \mathrm{~W} / \mathrm{m}^{2}$ (Figura 28.3). Algunos de los nuevos RCP contemplan los efectos de las políticas orientadas a limitar el cambio climático del siglo XXI.

Christophe Cassou [15] puntualiza que en climatología, el término proyección designa el cambio climático estimado en el transcurso del siglo en función de los diferentes escenarios socioeconómicos del IPCC. Esta proyección se elabora exclusivamente a partir de los únicos efectos de las perturbaciones del equilibrio radiativo (cambio del balance de radiación entrante en el sistema menos la radiación saliente), que se generan por el aumento de la concentración de los gases de efecto invernadero, debidos principalmente a las actividades humanas, en la composición de la atmósfera. Por construcción, las proyecciones no buscan predecir la cronología exacta de la variabilidad climática futura, se limitan a evaluar la respuesta del sistema climático a las perturbaciones de origen humano. La predicción, ya sea meteorológica, estacional o climática a una escala decadal, busca en cambio cuál es la trayectoria exacta del sistema. En las escalas decadales, esta trayectoria corresponde a la superposición; (1) de variaciones y oscilaciones lentas del sistema climático; (2) de variaciones de la radiación solar cuya periodicidad es del orden de once años; (3) de la actividad volcánica; (4) de la respuesta del sistema a los forzamientos antrópicos como en las proyecciones. Por eso, la predicción decadal es tan difícil de realizar al integrar todas estas influencias.

Acudiendo al glosario del IPCC, encontramos que se define una predicción climática como el resultado de una tentativa de estimación de la evolución real del clima en el futuro (por ejemplo, a escalas de tiempo estacionales, interanuales o a largo plazo). Como es posible que la evolución futura del sistema climático esté muy influida por las condiciones iniciales oceánicas, tales predicciones son, en general, de naturaleza probabilista (véase https://www.ipcc.ch/publications_and_data/ ar4/syr/fr/annexessannexes-2-3.html).

Los modelos climáticos ofrecen la posibilidad de anticipar la forma en que el sistema climático podrá ser modificado por la actividad humana en el transcurso del siglo XXI. Los estudios se apoyan en simulaciones numéricas que exploran la evolución del clima medio y de su variabilidad en función de diferentes escenarios socioeconómicos [6]. Este aspecto exploratorio queda recogido en la expresión proyección climática. El término proyección traduce, en consecuencia, que los resultados dependen de las hipótesis formuladas en las perturbaciones aplicadas al clima. Las proyecciones climáticas ofrecen, por tanto, una gama de posibilidades para el clima futuro. Este dependerá de cómo evolucione la sociedad mundial, de las tecnologías presentes y futuras, de las fuentes de energía utilizadas, del crecimiento de la población y de las acciones y políticas que se lleven a cabo en temas de cambio climático, entre otros factores. Es importante enfatizar que la proyección climática no es una predicción climática; ésta última trata de dar información sobre todas las situaciones posibles en un futuro relativamente cercano (no superior a un par 
de décadas) mientras que la primera proporciona información sobre el estado del clima a más largo plazo, condicionado por distintos escenarios socioeconómicos.

Las predicciones climáticas no intentan predecir la progresión día tras día del sistema sino la evolución de algún estadístico climático como los promedios estacionales, anuales o decenales o extremos, bien para una localidad en particular o un promedio global o regional. Las predicciones climáticas se generan con frecuencia con modelos que son los mismos o similares a los que producen simulaciones climáticas y proyecciones (evaluadas en el capítulo 9 del Informe del Grupo de Trabajo I del Quinto Informe de Evaluación del IPCC, 2013). Una predicción climática se consigue, generalmente, integrando las ecuaciones que rigen los procesos hacia delante en el tiempo a partir de condiciones iniciales basadas en observaciones. También se pueden obtener predicciones climáticas utilizando métodos estadísticos que relacionan las condiciones actuales con las futuras, utilizando relaciones estadísticas deducidas del comportamiento pasado del sistema. Por otra parte, la práctica habitual es que las proyecciones no se inicializan a partir del estado actual del sistema climático. A este respecto, no se ajustan a la visión tradicional de la predecibilidad expuesta por LORENZ ([51], cap. 12.2.3 en la página 158), aunque la variabilidad natural, variabilidad interna y los procesos estocásticos de múltiples escalas son también componentes importantes de la incertidumbre.

\subsubsection{SPC de conveniencia}

La técnica de SPC o ensembles permite elaborar no una previsión única sino un conjunto de predicciones, ligeramente diferentes las unas de las otras y reflejar las diferentes fuentes de incertidumbre, con el fin de caracterizar la probabilidad con la que un suceso dado se puede producir. Se encuentra en la base de los progresos conseguidos en las predicciones mensuales y estacionales, así como en las evoluciones del clima futuro (informes del IPCC).

Un ensemble puede generarse de muchas maneras diferentes y se ha explorado un rango amplio de métodos en predicción estacional $[70,72]$ pero no se han investigado, por ejemplo, de una forma completa y exhaustiva para la predicción decadal [18]. Los métodos que están siendo investigados incluyen las perturbaciones aleatorias añadidas a las condiciones iniciales, utilizando estados atmosféricos desplazados en el tiempo, haciendo uso de pasadas de asimilación paralelas $[20,22]$ y condiciones iniciales de océano perturbado $[56,88]$.

El enfoque multimodelo (sec. 13.5 en la página 174), utilizado ampliamente, consiste en generar ensembles de predicciones de una colección de modelos incrementando, en consecuencia, el muestreo de las condiciones iniciales y propiedades de los modelos. Los enfoques multimodelo se han empleado en distintas escalas temporales, desde la estacional-interanual (p. ej., DEMETER [62]), estacional-decadal (p. ej. $[59,83]$ ), en la simulación de cambio climático (p. ej., [41] capítulo 10; [54]) y en las predicciones decadales del proyecto ENSEMBLES [36, 75, 84] y las basadas en el CMIP5 evaluadas en la Sección 11.2.3 del AR5 ([73] https://www.ipcc.ch/pdf/assessment-report/ ar5/wg1/WG1AR5_Chapter11_FINAL.pdf). Un problema en el enfoque multimodelo es la interdependencia de los modelos climáticos utilizados en los sistemas de predicción actuales [45, 63].

En clima, se habla de SPC de conveniencia porque no son verdaderamente ensembles diseñados con técnicas específicas, sino que se toman todos los modelos generados, por ejemplo, para el Cuarto y Quinto Informes de Evaluación del IPCC (AR4 y AR5), procedentes de los proyectos de Intercomparación de Modelos Acoplados 3 y 5, CMIP3 y CMIP5 (de sus siglas en inglés), y se construye un «ensemble», dando el mismo peso a todos esos modelos $[41,73]$. La implicación de cómo estos ensembles multimodelo se crean es que el muestreo ni es sistemático ni es aleatorio. La distribución de los modelos es, por tanto, completamente arbitraria y puede ser diferente en un ensemble posterior; cambiando, en consecuencia, el resultado a pesar de no haberse producido cambios en el conocimiento del cambio climático. Incluso, para resolver el problema de pesado de los miembros individuales, el paso posterior continuará dependiendo de la distribución anterior que viene determinada por decisiones humanas y no puede interpretarse en un sentido científico. Otra cara del problema es que los modelos no están diseñados para cubrir el rango completo del comportamiento o incertidumbre que se sabe que existe. No es algo sorprendente, ya que todos los modelos se ajustan ( $t u$ nean) y mejoran para coincidir con las observaciones, tanto como sea posible.

La fuerza del enfoque de los conjuntos de conveniencia radica en que cada modelo difiere substancialmen- 
te en sus hipótesis estructurales y que cada uno de ellos se ha examinado de forma extensiva. La credibilidad de su predicción o proyección procede de la evaluación de su simulación del clima actual frente a un rango amplio de observaciones. Sin embargo, existen limitaciones importantes en este enfoque. El ensemble no ha sido diseñado para examinar el rango de posibles resultados. Su tamaño es demasiado pequeño (por regla general, del orden de 10-20 miembros) para proporcionar estimaciones robustas de los escenarios más probables y de las incertidumbres asociadas y por tanto, es difícil de utilizar en evaluaciones de riesgos.

\subsubsection{Predicción estacional: enfoques es- tadístico y dinámico}

Para la predicción a escala estacional coexisten dos grandes corrientes metodológicas: la estadística y la dinámica. En el caso de los enfoques dinámicos nos centraremos en el sistema del ECMWF, mientras que los estadísticos establecen las relaciones, observadas en el pasado, entre la circulación general prevista y las escalas locales, para prever los estados futuros, y como ejemplo nos centraremos en el modelo S-ClimWaRe desarrollado por Agencia Estatal de Meteorología (AEMET) para la predicción de la precipitación invernal en España.

Como ejemplo de enfoque dinámico, el Sistema integrado del ECMWF (IFS [40], sec. 19.2 en la página 291) lidera la mejor predicción numérica del tiempo por conjuntos en el medio plazo [29, 30]. Tiene también un rango de diferentes productos de predicción con vencimientos de hasta varios meses (véase Tabla para una lista completa de productos disponibles). La predicción de alta resolución del ECMWF tiene un horizonte de 10 días y una resolución horizontal de unos $9 \mathrm{~km}$ con orografía de unos $16 \mathrm{~km}$ (sec. 19.2 en la página 291). Las predicciones del tiempo se basan frecuentemente en las técnicas de ensembles para representar de forma adecuada las incertidumbres [49] y el ensemble del ECMWF consiste en 51 predicciones emitidas dos veces al día con un alcance de 15 días. La predicción mensual se integra en esta predicción de 15 días extendiendo el rango de predicción a 32 días dos veces por semana. El sistema de predicción estacional se corre una vez al mes con un tiempo de validez para varios meses (S4, [57]). A estos sistemas se les incorporan unos suplementos, como un conjunto de retropredicciones (hindcasts, en la terminología inglesa), que son predicciones que se han corrido a toro pasado para los últimos 18 años con el modelo de predicción actual. Las retropredicciones se usan, ya sea para calcular las climatologías de los modelos (sec. 27.7.1 en la página 419), o bien para calibrar la predicción antes de su uso en las aplicaciones derivadas.

El ECMWF, como se ha citado, realiza dos veces por semana una predicción numérica hasta un mes. Las predicciones mensuales (predicciones de 32 días) se producen de forma operacional desde octubre de 2004, aunque se habían iniciado ya en marzo de 2002. En la configuración actual, las predicciones mensuales se generan extendiendo las integraciones de conjunto de 15 días a 32 días dos veces por semana (a 00 UTC). Las predicciones se basan en el SPC de medio plazo (ECENS, 19.3 en la página 293) que forma parte del Sistema de Predicción Integrado del ECMWF (IFS). En la actualidad (2018), el ENS incluye una integración de 51 miembros con una resolución espectral O640 (aproximadamente una resolución horizontal de $18 \mathrm{~km}$ ) hasta el día de predicción 15, y O320 (unos $36 \mathrm{~km}$ ) posteriormente (días 16-46). Las perturbaciones iniciales se generan utilizando una combinación de vectores singulares y perturbaciones generadas utilizando asimilación de datos por conjuntos (EDA, [11, 39], sec. 16.2.5 en la página 248); por otro lado, las incertidumbres de los modelos se simulan recurriendo a dos esquemas estocásticos ([4, 60, 67], sec. 17.4.4 en la página 269). La climatología utilizada para calibrar las predicciones en tiempo real se calcula utilizando la serie de retropredicciones que incluye solo 5 miembros de las integraciones de 32 días con la misma configuración que las predicciones en tiempo real, empezando en el mismo día y mes que la predicción en tiempo real sobre los últimos 20 años (sec. 27.7.1 en la página 419). Las retropredicciones son creadas un par de semanas antes de la correspondiente predicción en tiempo real. Esta estrategia para las retropredicciones es diferente de la utilizada en la predicción estacional donde la versión del modelo se congela durante unos pocos años y las retropredicciones se crean tan solo una vez. VITART [77] documentó que, en promedio, la habilidad (skill, sec. 15.2.4 en la página 212) de las predicciones mensuales para las semanas 2 a 4 , ha mejorado significativamente en la década pasada.

El sistema de predicción estacional del ECMWF consiste en un análisis oceánico para estimar el estado inicial del océano, un modelo de circulación general global acoplado océano-atmósfera para calcular la evolución del océano y atmósfera, y una serie de 
posprocesos para crear productos de predicción a partir de la salida numérica bruta (véase para más detalle https://www.ecmwf.int/en/forecasts/ documentation-and-support/long-range).

Además de la predicción estacional que se hace cada mes, se elabora una predicción anual cuatro veces al año, siendo las fechas de comienzo el 1 de febrero, 1 de mayo, 1 de agosto y 1 de noviembre. El rango de la predicción es 13 meses. Las predicciones de rango anual se corren como una extensión de la predicción estacional y se hacen utilizando el mismo modelo pero con un tamaño del ensemble (número de miembros, 13.4.1 en la página 173) más pequeño. Tanto las retropredicciones como las predicciones en tiempo real tienen un tamaño de 15 miembros. Las predicciones de rango anual se diseñan principalmente para proporcionar una predicción del fenómeno El Niño. En el momento actual, tienen un estatus experimental más que operacional.

\subsubsection{Ejemplo de sistema de predicción estacional: S-ClimWaRe}

Como ejemplo de un modelo empírico sencillo de predicción estacional tenemos el modelo S-ClimWaRe desarrollado por AEMET [78].

Se denomina servicio climático al suministro de información climática que ayude a la toma de decisiones, tanto de las personas como de las organizaciones. Las predicciones climáticas estacionales son un componente fundamental de los servicios climáticos. El proyecto europeo FP7 EUPORIAS (noviembre 2012 enero 2017 [13, 35]), ha trabajado en el desarrollo de sistemas de previsión de impactos a escala estacional y decadal para el apoyo a la toma de decisiones dependientes del clima, siguiendo las directrices del Marco Mundial para los Servicios Climáticos, y fomentando el desarrollo de servicios climáticos en sectores clave, incluyendo agua, energía, salud, transporte, agricultura y turismo. Un proyecto demostrativo del valor de las predicciones estacionales, surgido en EUPORIAS como «caso de estudio», es el servicio climático piloto destinado a apoyar la gestión de los embalses en España denominado $\mathrm{S}$-ClimWaRe (Seasonal Climate predictions in support of Water Reservoirs management).
S-ClimWaRe está siendo puesto en funcionamiento por un equipo multidisciplinar cuyos integrantes pertenecen a la Dirección General del Agua, las Confederaciones Hidrográficas del Ebro, Duero, Tajo y Miño-Sil, AEMET, CETaqua (institución española que trabaja en el ciclo integral del agua) y la Universidad Politécnica de Valencia.

El «caso de estudio» S-ClimWaRe se apoya en el conocimiento y predecibilidad de patrones atmosféricos (y también en algunos casos oceánicos), que son impulsores o drivers de la variabilidad climática observada en ciertos lugares y estaciones del año. La metodología que se ha empleado es una adaptación de la ya utilizada en sistemas probados con éxito en otros países, fundamentalmente de Asia y Norteamérica, y que están basados en la predecibilidad del clima a escala estacional que proporciona el fenómeno El Niño-La Oscilación del Sur ([10], 29.2.1 en la página 484). En el caso de S-ClimWaRe, se explota la conocida influencia de la Oscilación del Atlántico Norte (NAO [82], 29.2.2 en la página 485 y párrafo siguiente) en la variabilidad hidrológica en amplias zonas de España [65].

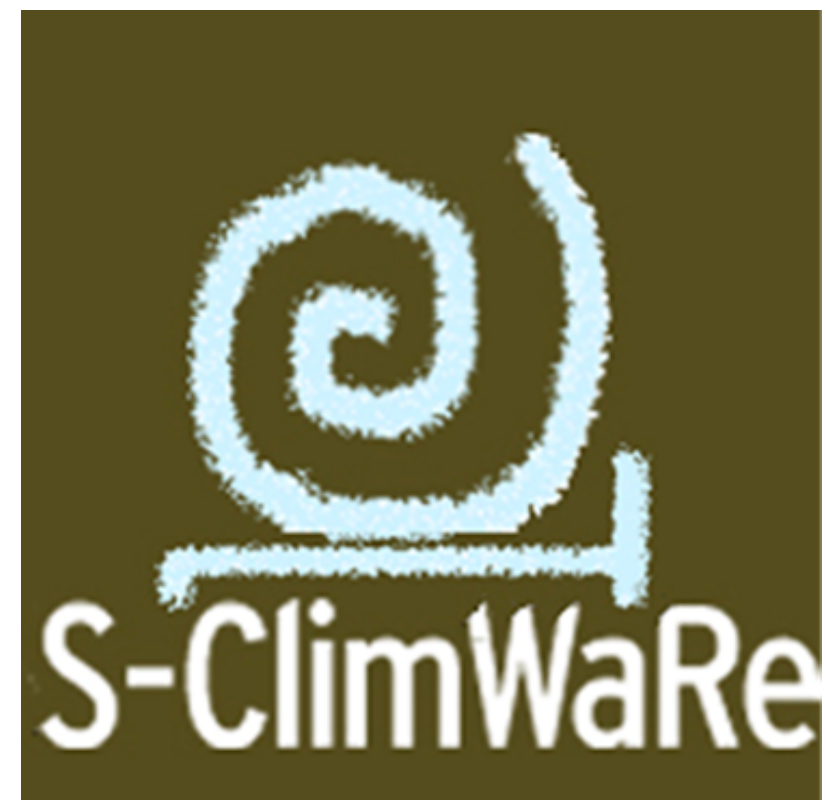

Figura 28.4: S-ClimWaRe: Un servicio climático desarrollado en AEMET basado en predicción estacional para apoyar la gestión de los embalses en España. 

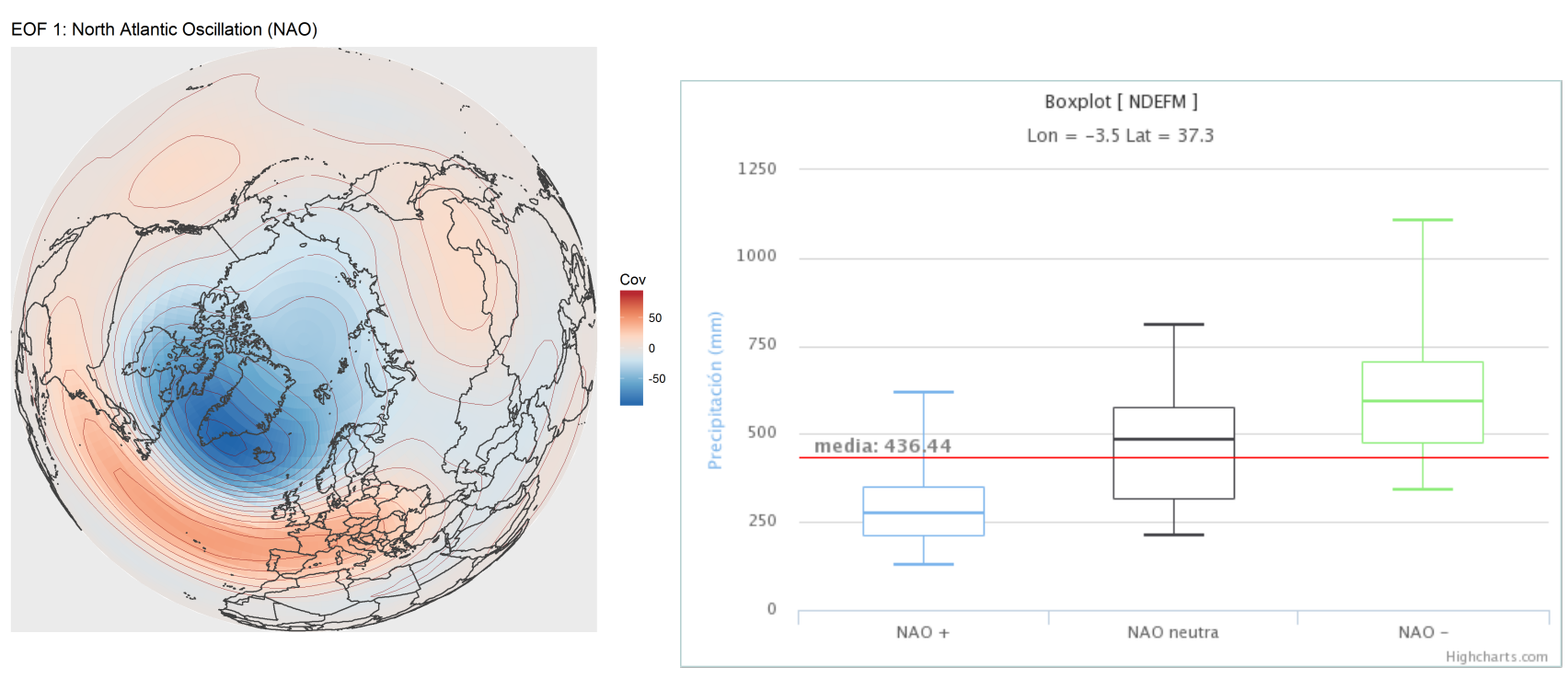

Figura 28.5: Patrón espacial de la Oscilación del Atlántico Norte, NAO (izquierda) y su influencia en la precipitación acumulada en el periodo invernal -noviembre a marzo- en un punto de Andalucía representada por diagramas de cajas (boxplot) correspondientes a los inviernos con NAO positiva, neutra y negativa (derecha).

Oscilación del Atlántico Norte (North Atlantic Oscillation, NAO) y variabilidad de la precipitación invernal en España. La estructura espacial de la NAO en su fase positiva/negativa corresponde a anomalías de presión negativas/positivas en la zona de Islandia y a anomalías positivas/negativas en las latitudes medias del Atlántico Norte, como se muestra en la Figura 28.5, parte izquierda.

La NAO tiene una marcada influencia en la precipitación invernal en gran parte de la España peninsular. En la Figura 28.5, parte derecha, se presenta un ejemplo del impacto de este patrón atmosférico en la variabilidad observada en la precipitación invernal (de noviembre a marzo) desde 1951 hasta la actualidad, en un punto de Andalucía oriental. Se representa, mediante el uso de boxplots (ver sec. 13.6.8 en la página 183), la distribución estadística (mediana, cuartiles y valores máximo y mínimo) de la precipitación invernal en ese lugar, dependiendo de la fase de la NAO. Se puede observar que los inviernos con NAO positi$\mathrm{va} /$ negativa se corresponden, en general, con periodos secos/húmedos.

Gran parte de la variabilidad de la NAO es debida a procesos internos de la dinámica atmosférica y a sus retroalimentaciones, lo que hace que sea difícil predecir correctamente este patrón atmosférico en horizontes de escala estacional por parte de la mayoría de los modelos de circulación general océano-atmósfera existentes [14]. Como consecuencia de ello, la habilidad de sus predicciones de precipitación en las zonas fuertemente influenciadas por la fase de la NAO es demasiado baja para poder ser de utilidad en la toma de decisiones.

A pesar de ello, en invierno, una parte de la variabilidad de la NAO puede ser forzada externamente en escalas temporales largas, por ejemplo, por la extensión de la capa de nieve en Eurasia. COHEN y JONES [17] han demostrado que, en invierno, este importante patrón de variabilidad climática está asociado de forma estadísticamente significativa con el avance de la cobertura de nieve en otoño en esta zona del hemisferio norte. Científicos de la Universidad de Cantabria, en colaboración con estos autores, han puesto de manifiesto que existe una capacidad predictiva de la precipitación invernal en España basada en este avance de la nieve [7]. Utilizando estos resultados, en S-ClimWaRe se ha optado por utilizar una formulación estadística para la predicción climática estacional del próximo invierno, y se ha desarrollado un modelo empírico de predicciones probabilistas de aportaciones a los embalses y de precipitación utilizando el avance de la nieve en Eurasia en otoño como fuente de predecibilidad de la NAO invernal, que a su vez lo será de las aportaciones o de la precipitación [78].

La incertidumbre de las predicciones estacionales generadas por este sistema estadístico se estima generando un ensemble de predicciones, en el que los miembros corresponden a distintas situaciones históricas, si bien aparecen con una mayor, igual, o menor frecuencia que la ocurrida en el pasado. 


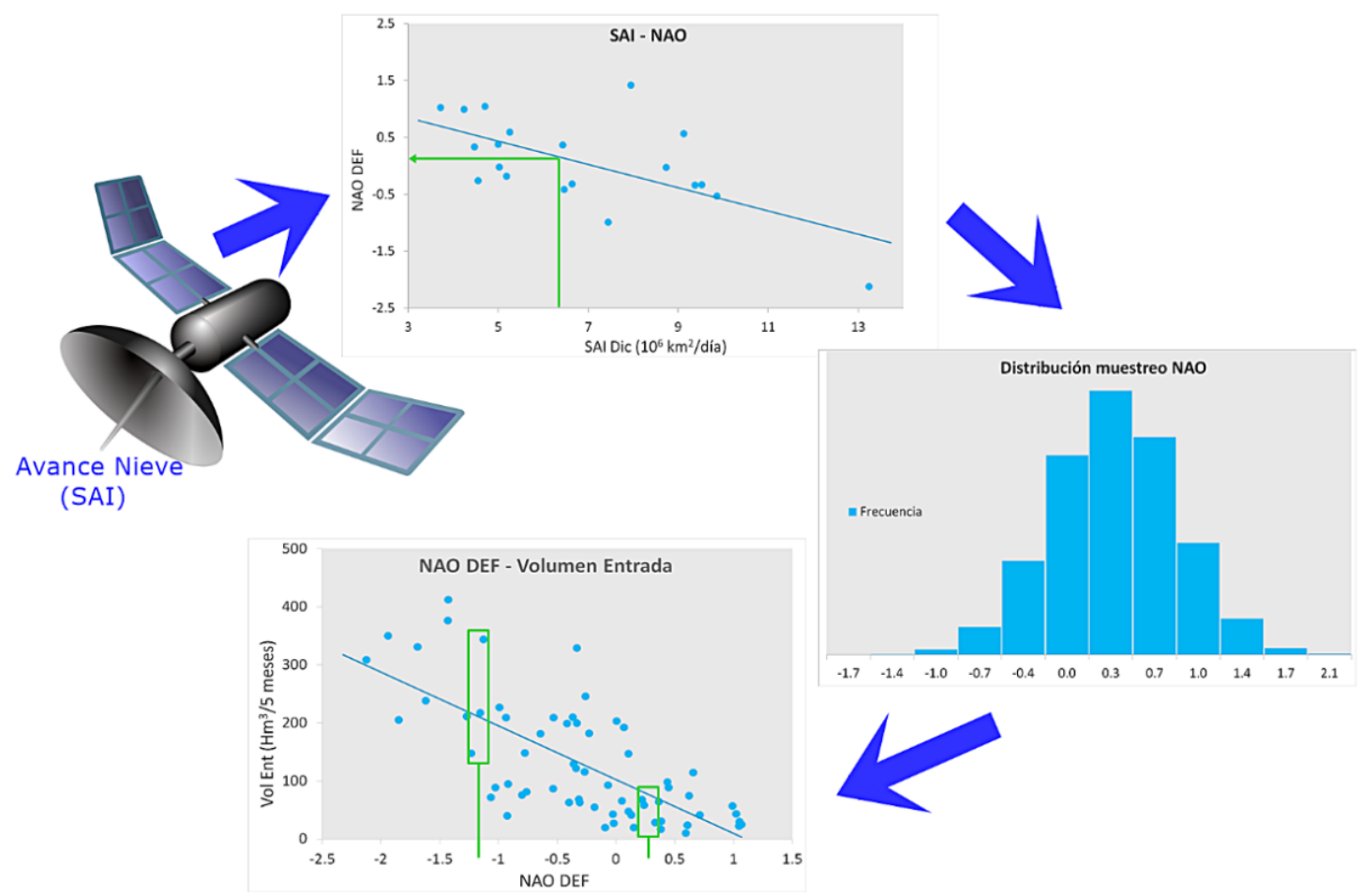

Figura 28.6: Esquema del sistema estadístico de predicción estacional desarrollado en S-ClimWaRe.

Descripción del sistema empírico de predicción estacional. En el desarrollo del sistema de predicción estacional de aportaciones a los embalses se ha seguido la metodología propuesta por el International Research Institute for Climate and Society [10]. Una descripción completa del mismo puede encontrarse en Voces et al. [78]. Se ilustra en la Figura 28.6

El módulo de predicción puesto en funcionamiento en S-ClimWaRe consiste en un sistema estadístico para pronosticar, a partir del avance de la nieve en Eurasia (que se calcula a comienzos de noviembre utilizando productos de observación satelitales), un ensemble de valores de la aportación para el periodo invernal (de noviembre a marzo) en cada uno de los embalses.

La predicción probabilista de aportaciones se realiza en dos etapas:

1. La primera consiste en predecir la magnitud y fase de la NAO en los próximos meses. Con el valor del avance de la nieve se pronostica el índice de este patrón invernal utilizando una regresión lineal. La incertidumbre de este valor previsto de la NAO se estima mediante el muestreo de una distribución normal centrada en el valor del índice previsto de forma determinista, generando así un ensemble de valores previstos de la NAO invernal.
2. La segunda etapa de la predicción es local y se realiza de forma independiente en cada uno de los embalses. A partir del valor del índice de la NAO previsto por cada uno de los miembros del ensemble anterior se buscan, en la serie histórica, las aportaciones al embalse ocurridas en el pasado correspondientes a los $K$ años con el índice NAO invernal más parecido al previsto por el miembro en cuestión. La utilización de este algoritmo $K_{n n}$ (K-nearest neighbors [46]), evita hacer hipótesis sobre la forma de la distribución estadística de la incertidumbre de las predicciones de aportaciones en este segundo paso de la predicción.

De esta forma, el ensemble de aportaciones generado localmente en cada embalse está compuesto por 1500 valores de aportaciones tomados de su serie histórica. Cada suceso tendrá una frecuencia asociada, el número de veces que aparece en el ensemble de predicción. Esta frecuencia está directamente relacionada con la probabilidad de esa aportación.

El modelo desarrollado se aplica de forma similar a la predicción estacional de la precipitación sin más que sustituir la serie de valores observados de aportaciones al embalse por la precipitación. 
Salidas del sistema. Las salidas del modelo empírico de predicción estacional se posprocesan para generar productos probabilistas y se verifican de forma similar a las salidas de los modelos dinámicos de predicción estacional. En S-ClimWaRe, el producto que se suministra a los usuarios es la probabilidad de un invierno húmedo, normal o seco, calculando la probabilidad que la función de distribución, que forman los miembros del ensemble, otorga a cada una de las categorías definidas por los terciles de la serie de predicciones invernales realizadas sobre un periodo histórico retrospectivo con las que se compara la predicción para el próximo invierno. Para evaluar la precisión y habilidad de estas predicciones probabilistas, se ha desarrollado un paquete completo de verificación objetiva con métricas estándar.

El servicio climático S-ClimWaRe, además del sistema estadístico de predicción estacional probabilista acompañado de su posproceso y verificación objetiva, también incorpora herramientas de análisis de la variabilidad hidrológica y climática ligadas a la NAO. A estas herramientas y productos de predicción estacional se accede mediante un portal web de información, basado en tecnología GIS (Geographical Information Systems [50]), que está siendo diseñado conjuntamente con los usuarios finales que integran el equipo de trabajo. Para todo ello, S-ClimWaRe combina datos de observación in situ hidrológicos y meteorológicos con series de precipitación en malla, con productos satelitales de cobertura de nieve y con la serie histórica de índices de la NAO obtenidos a partir de reanálisis atmosféricos. El servicio climático se completa con el modelo de previsión de riesgos de los embalses SIMRISK [33], desarrollado por la Universidad Politécnica de Valencia, y que ha sido adaptado para utilizar como entrada las predicciones probabilistas de aportaciones a los embalses.

El sistema SIMRISK, alimentado por predicciones estacionales de aportaciones producidas para un periodo histórico retrospectivo, está produciendo previsiones de riesgos de llenado de distintos niveles del embalse y de satisfacción de la demanda para las distintas condiciones que se dieron cada año del periodo. Estas previsiones del estado del sistema permiten analizar posibles oportunidades de actuación preventiva, tanto en años de sequía como en aquellos muy húmedos en los que se produjeron inundaciones. Los resultados alcanzados en el servicio S-ClimWaRe completo en 2016 están disponibles en el informe online publicado por el MAPAMA [79] (enlace actualizado 16-102018 a página del Ministerio para la Transición Ecológica (MITECO)): https://www.miteco.gob.es/en/ agua/temas/evaluacion-de-los-recursos-hidricos/ Prediccion-estacional-gestion-embalses.aspx.

El servicio climático S-ClimWaRe, que se ha desarrollado con una arquitectura modular, se basa en un ciclo continuo de evaluación y desarrollo para satisfacer los requisitos de los usuarios finales, a través de la mejora de sus distintos componentes. Entre ellos, la evolución hacia la utilización de salidas de los modelos climáticos de circulación general océano-atmósfera, una vez se consiga predecir el estado de la NAO del invierno venidero con una mayor habilidad.

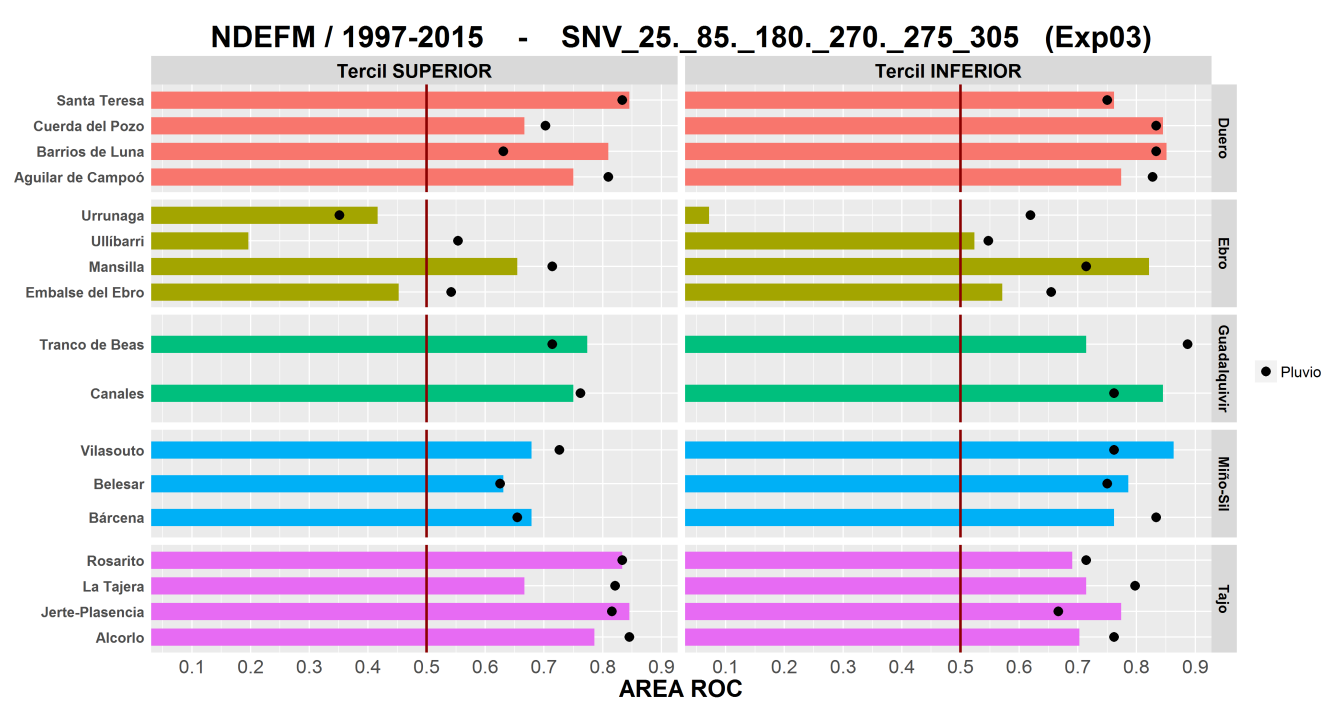

Figura 28.7: Área ROC ([32], sec. 15.9.6 en la página 231) para las categorías invierno húmedo/seco (columnas izquierda/derecha) de las predicciones de aportaciones a cada uno de los embalses (barras de colores) y de la precipitación (puntos negros). 
Evaluación de las predicciones probabilistas del sistema empírico de predicción estacional. Los usuarios finales integrantes del equipo S-ClimWaRe, han seleccionado una serie de embalses de las cuencas del Duero, Tajo, Ebro, Miño-Sil y Guadalquivir, en los que se ha probado la utilización de estas predicciones climáticas estacionales probabilistas generadas con el sistema empírico que se ha desarrollado.

La habilidad del sistema empírico empleado para predecir la precipitación y las aportaciones a los embalses en el próximo invierno, se ha evaluado mediante la realización de predicciones estacionales sobre un periodo histórico retrospectivo, o hindcast, en el que no se han incluido los datos del año a predecir (procedimiento de validación cruzada [87]).

Los índices de verificación utilizados para evaluar las predicciones probabilistas miden, entre otros, la capacidad de discriminación (mediante el área ROC [32], sec. 15.9.6 en la página 231), y la habilidad respecto a la utilización de la climatología muestral (Brier Skill Score [8, 42, 53], sec. 15.9.8 en la página 232), o el coeficiente de correlación de la media del ensemble de predicciones con la observación [78].

La Figura 28.7 muestra el valor del área ROC ([32], 15.9.6 en la página 231) para las categorías invierno húmedo/seco (columnas izquierda/derecha) de las predicciones de aportaciones a cada uno de los embalses (barras de colores) y de la precipitación (puntos negros). Para los casos en los que se haya observado a posteriori un evento (por ejemplo, invierno húmedo), el sistema de predicción es capaz de discriminar positivamente la ocurrencia de la no ocurrencia del evento si el valor del área ROC es superior a 0.5. En el caso de una discriminación perfecta, el valor del área ROC es igual a 1. Un valor del área ROC igual a 0.5 se obtiene si el sistema de predicción no es capaz de discriminar la ocurrencia de la no ocurrencia del evento observado. Valores inferiores a 0.5 indican una discriminación negativa del sistema de predicción, y sugieren que con un invierno húmedo observado, el sistema de predicción habría otorgado una mayor probabilidad a que no fuera un invierno húmedo que a lo contrario.

Los resultados obtenidos son muy satisfactorios en los embalses del Guadalquivir, Duero, Tajo, Miño-Sil y el embalse de Mansilla en la cuenca del Ebro, e indican que se discrimina razonablemente bien en esas zonas a comienzos de noviembre el carácter húmedo/seco del siguiente trimestre invernal.

\subsubsection{Fiabilidad}

Un sistema de predicción se considera fiable si las probabilidades de predicción para un suceso concuerdan con las frecuencias condicionales de la ocurrencia real de ese suceso (sec. 15.9.4 en la página 226).

Las predicciones climáticas de largo plazo, exactas y precisas, son imposibles de obtener debido a la naturaleza caótica del sistema climático. Las predicciones estacionales son probabilistas, lo que significa que proporcionan la probabilidad de ocurrencia de ciertos resultados más que una predicción de tipo numérico o de tipo si-no. Por esta razón, la información sobre la fiabilidad de las predicciones climáticas es crucial para cualquier usuario de información climática de cara a saber la utilidad de esas predicciones para apoyar el proceso de toma de decisiones.

Cuando se predice el clima futuro, deseamos utilizar el número mayor de modelos fiables y tener una idea acerca de cuán fiables son esas predicciones. El denominado diagrama de fiabilidad (sec. 15.9.4 en la página 226) es una herramienta gráfica utilizada para evaluar la fiabilidad de las predicciones probabilistas, climáticas por ejemplo. Describe la relación estadística entre la probabilidad de una predicción predicha y la frecuencia estadística condicionada con la que se observa realmente la predicción. De un modo muy general, las predicciones con una gran fiabilidad tienen habilidad (skill) y son exactas desde el punto de vista probabilista, lo que significa que tienen una incertidumbre baja $y$, en consecuencia, un error de predicción relativamente bajo (para profundizar estos aspectos puede consultarse el capítulo dedicado a verificación 15 en la página 207).

\subsubsection{Tendencias actuales hacia el esque- ma seamless}

La multiplicación de los sistemas de predicción (corto plazo, medio plazo, predicción mensual, predicción estacional), cada uno con sus propias cadencias de actualización suscita la cuestión de la claridad / visibilidad y de la compatibilidad de los diferentes productos para los usuarios. Ello lleva a los servicios meteorológicos a subrayar el concepto de predicciones sin discontinuidad o sin costuras (seamless forecasts, en inglés). Este concepto puede describirse como la apuesta para hacer compatibles predicciones de diferentes plazos, atendiendo a su concepción de base, su contenido y 
su formato. Se habla de predicción sin costura para la producción de predicciones a 24 h, a 10 días, a un mes, a 6 meses, a 10 años, o incluso de escenarios climáticos para el fin de siglo. Esta expresión enfatiza la necesidad de la puesta en común de desarrollos científicos y técnicos.

Desde hace aproximadamente una decena de años, se observa una notable convergencia de métodos y cuestionamientos científicos en la predicción del tiempo y del clima. La toma en consideración, cada vez más completa, de las interacciones entre los diferentes compartimentos del ambiente se ha vuelto necesaria y conduce, más allá de las diferencias de escalas temporales y espaciales, a una semejanza técnica creciente entre las herramientas de modelización del tiempo y del clima, lo que permite contemplar economías de desarrollo y de mantenimiento de los códigos. El empuje creciente en el uso de las observaciones in situ y satelitales para inicializar y validar los modelos numéricos es otra fuente de convergencia entre los dominios de la meteorología y del clima. Estas tendencias generales conducen a los servicios meteorológicos a avanzar el concepto de las predicciones «sin costuras»o 0 «sin discontinuidad».

Uno de los grandes desafíos lanzados por el desarrollo de los servicios climáticos es progresar en la predicción de las fluctuaciones climáticas en escalas espaciales relativamente finas y para horizontes temporales que van de la semana a la década. Estas fluctuaciones se superponen a la tendencia de fondo del cambio climático antrópico (por ejemplo, a pesar de la tendencia hacia un clima más cálido y seco en España debido al calentamiento global, debido a estas fluctuaciones naturales superpuestas los meses de febrero y marzo de 2018 fueron especialmente lluviosos en España). Su predicción requiere progresos importantes en la comprensión de la variabilidad natural del clima, que se traduce en oscilaciones climáticas. Hay que comprender los mecanismos que hacen que estos fenómenos se desarrollen, sus interacciones, evaluar su predecibilidad y mejorar los aspectos del estado inicial o de la física de los modelos que son esenciales para su predicción. Resultados recientes subrayan, por ejemplo, el papel probable de la convección nubosa y de la estratosfera para favorecer la emergencia de ciertas oscilaciones. Estos estudios deben tener también en cuenta el océano, la humedad de los suelos, la composición de la atmósfera, la criosfera y la variabilidad solar, estudios que deben apoyarse en una base larga de observaciones homogéneas del sistema Tierra que se encuentran condicionadas en parte por el desarrollo de los programas internacionales de los reanálisis de la atmósfera, del océano y de las superficies continentales.

Sin embargo, este esfuerzo no ha concluido, ni es fácil de continuar. El espectro de escalas, de procesos y de usos a cubrir es cada vez más amplio, con el desarrollo de la predicción a escala de los fenómenos convectivos individuales (sec. 22.1.2 en la página 334 y sec. 22.1 en la página 334) y el acoplamiento con la composición de la atmósfera. El uso creciente de módulos desarrollados inicialmente en marcos diferentes exige esfuerzos importantes para garantizar la compatibilidad y la versatilidad de las diferentes opciones. Se precisarán nuevos esfuerzos de racionalización de los códigos para proseguir la elaboración de un ensemble durable y unificado al servicio de la predicción del tiempo y del clima. En esta línea, el enfoque de unificación de los códigos se extenderá al dominio de la química de la atmósfera. Una nueva biblioteca (library) común de códigos para la predicción de la calidad del aire y el estudio de las interacciones química-clima se desarrollará y será progresivamente implantada en las herramientas actuales. Integrará los avances procedentes del conjunto de la comunidad científica francesa en química de la atmósfera.

Ya Christophe CAssou en 2008 mencionaba que salvar el salto entre las escalas espacio-temporales de tiempo y clima constituía un reto significativo al que se enfrentaba la comunidad atmosférica. En concreto, el progreso tanto en el rango de medio plazo y en la predicción climática, desde la estacional a la interanual, reside en nuestra comprensión de los patrones de tiempo recurrentes y en la identificación de causas específicas responsables del favorecimiento de su ocurrencia, persistencia o transición. Dentro de este marco de referencia, se presentan pruebas de que la principal oscilación climática intraestacional en los trópicos es la oscilación de MADDEN-JULIAN (MJO [52], de sus siglas en inglés) que controla parte de la distribución y secuencias de los cuatro tipos de tiempo definidos en la región Atlántico Norte-Europa en invierno. Los regímenes de la oscilación del Atlántico Norte (NAO) son los más afectados, permiten la predecibilidad de su fase para el medio plazo, excediendo el límite de una semana que se le asocia a menudo. La relación tropical-extratropical -con retardo-, es asimétrica. Los eventos NAO (+) responden fundamentalmente a un tren de ondas de baja frecuencia en las latitudes medias iniciada por la MJO en el centro y oeste del Pacífico tropical oeste y que se propaga hacia el este. Los precursores para los eventos NAO (-) 
se encuentran en el este del Pacífico tropical-Atlántico occidental, conduciendo a cambios a lo largo de las trayectorias de tormentas (storm tracks, en inglés) del Atlántico Norte. Los diagnósticos de roturas de onda tienden a apoyar el precondicionamiento de la MJO y el papel de los torbellinos transitorios al establecer la fase de la NAO. Esta prometedora habilidad (skill) podría ser de importancia considerando la estrecha relación entre los regímenes de tiempo y las condiciones medias y las probabilidades de sucesos extremos en Europa. Estos descubrimientos son útiles para acentuar todavía más la necesidad de simular y predecir mejor la dinámica del acoplamiento océano-atmósfera en la región tropical, que es una fuente de la predecibilidad de medio a largo plazo (talón de Aquiles de la predicción sin costuras).

Si el mismo SPC (ensemble multimodelo) se utiliza tanto para predicción estacional como para predicción de cambio climático, entonces la validación de las predicciones probabilistas en la escala de tiempo más corta puede utilizarse para mejorar la veracidad de las predicciones probabilistas en la escala de tiempo más larga. Esta mejora vendría de los procesos de evaluación en común entre la predicción estacional y las escalas temporales de la proyección climática, tales como la respuesta atmosférica a las temperaturas de la superficie del mar. Conviene insistir que procesos tales como el acoplamiento atmósfera-océano, que son relevantes para el problema de la predicción estacional, también desempeñan un papel en determinar el impacto de algún forzamiento climático dado, en el mismo sistema climático. La técnica de calibración proporciona una manera de cuantificar la debilidad en aquellos enlaces a la cadena común, tanto en la predicción estacional como en las escalas de tiempo del cambio climático.

\subsection{Predicción mensual}

La principal motivación para la predicción mensual es investigar la predecibilidad en el rango temporal de 10 a 30 días. Se trata de una escala temporal a caballo entre la predicción de tiempo a plazo medio y la predicción estacional, representando dos problemas diferentes. La predicción de tiempo a plazo medio es esencialmente un problema de valores iniciales atmosféricos, ya que esta escala temporal es demasiado corta para que las variaciones en el océano tengan un impacto significativo en la circulación atmosférica. A partir de diez días, la variación de los océanos tiene una influencia significativa en la atmósfera. Por tanto, hay que tenerla en cuenta en los modelos que simulan su evolución. Al utilizar modelos acoplados océanoatmósfera, es posible también prever las condiciones medias de temperatura y de precipitaciones más allá de 10 días.

El rango temporal de 10 a 30 días es probablemente suficientemente corto para que la atmósfera conserve la memoria de su condición inicial y lo suficientemente largo para que la variabilidad oceánica pueda tener un impacto en la circulación atmosférica. En consecuencia, las predicciones mensuales del ECMWF se producen a partir de integraciones acopladas océanoatmósfera.

Una importante fuente de predecibilidad sobre Europa en el rango 10-30 días se cree que podría atribuirse a la MJO [23]. La MJO es una oscilación tropical de periodo comprendido entre 40-50 días. Varios artículos (p. ej. [25]) sugieren que el acoplamiento océano-atmósfera tiene un impacto significativo en la velocidad de propagación de un evento MJO en el Índico ecuatorial y en el Pacífico occidental. En consecuencia, el uso de un sistema acoplado océanoatmósfera facilitaría la captación de algunos aspectos de la variabilidad de la MJO.

\subsubsection{Particularidades de las predicciones mensuales del ECMWF}

Se ha comprobado que la habilidad de las predicciones mensuales del ECMWF ha mejorado desde su inicio. Las mejoras en las puntuaciones (scores en inglés, ver sec. 15.2.3 en la página 211) relacionadas con la habilidad son, en particular, grandes para la predicción de la MJO, una fuente importante de predecibilidad en la escala de tiempo subestacional. Respecto a las regiones extratropicales del hemisferio norte, la habilidad de la predicción de la NAO y de las anomalías de temperatura a 2 metros también ha aumentado. VITART [77] muestra que una proporción grande de las mejoras en las puntuaciones de la habilidad de la NAO podrían atribuirse a las mejoras en la predicción de la MJO. Esas mejoras son debidas a una combinación de mejoramientos en el modelo, condiciones iniciales (asociadas con mejores esquemas de asimilación de datos, mejoras de modelo y uso de nuevos sistemas de observación) y diseño de SPC más fidedignos al perfeccionar la simulación de las incertidumbres. Indirectamente, los cambios recientes en el ECENS de medio plazo ayudarán a aumentar la 
habilidad de la predicción subestacional. Los cambios futuros incluirán la implementación de un modelo de hielo marino en lugar de un hielo marino persistente y una mayor resolución del modelo oceánico (de $1^{\circ}$ a $\left.1 / 4^{\circ}\right)$.

\subsubsection{Productos}

Dos veces por semana, el ECENS (días 1-15) se extiende hasta 46 días (días 16-46). Los productos del así llamado ENS extendido o mensuales comprenden ensembles de predicciones individuales y posprocesos de condiciones promedio (por ejemplo, promedios semanales) así como la incertidumbre asociada (más información en [80] y [31]). Los siguientes subconjuntos están disponibles en las pasadas de los lunes y jueves: (VI-i) Medias semanales de las medias de ensemble (incluyendo productos de retropredicción); (VI-ii) Anomalías medias semanales de las medias del ensemble; (VI-iii) Medias semanales de los miembros individuales del ensemble (incluyendo productos de retropredicción); (VI-iv) Anomalías medias semanales de los miembros individuales del ensemble ; (VI-v) Pasadas de predicción individuales (incluyendo productos de retropredicción); (VI-vi) Probabilidades (productos semanales). La Figura 28.8 muestra algunos ejemplos.

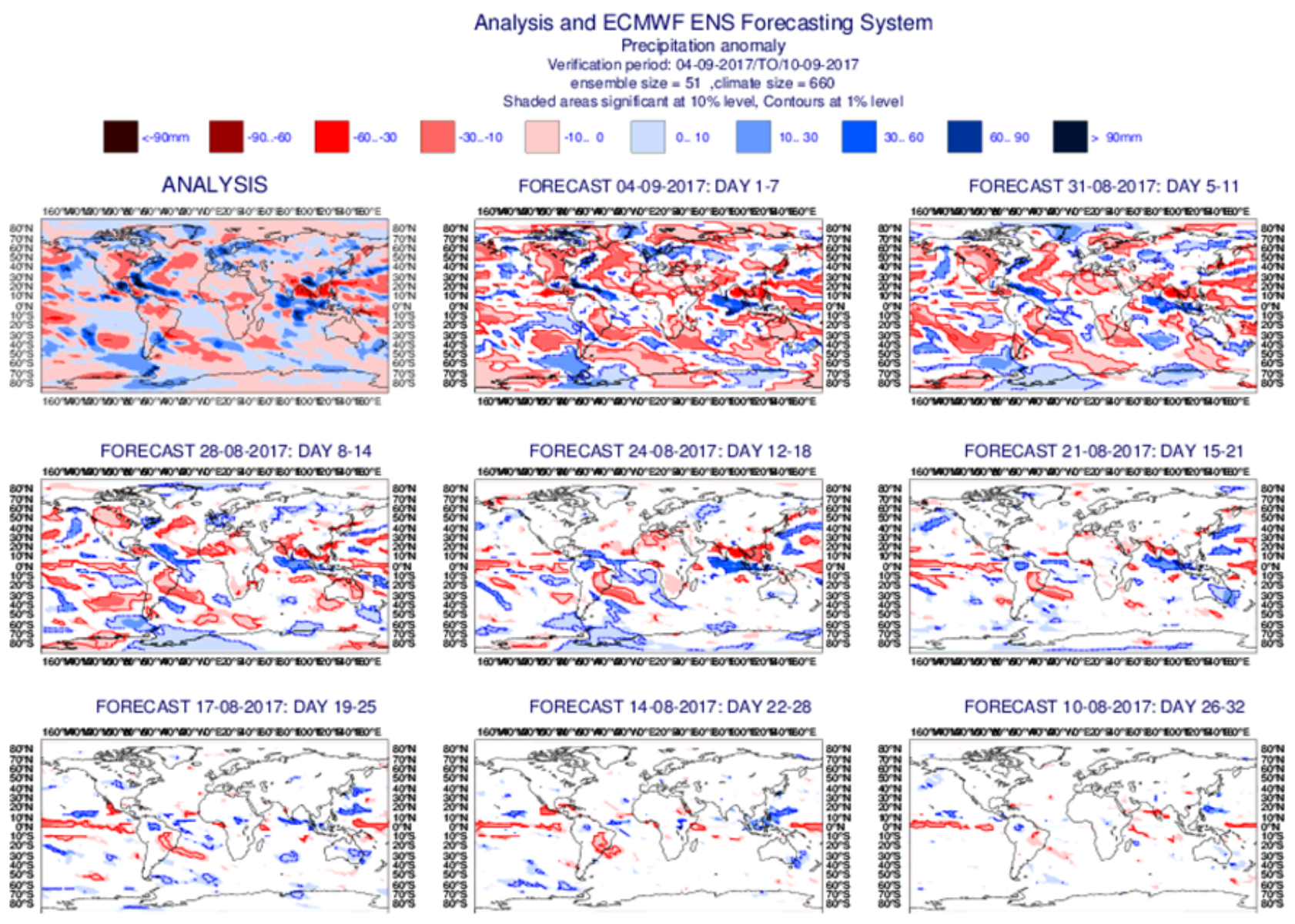

Figura 28.8: Anomalías medias semanales respecto al clima de los últimos 20 años. El mapa superior izquierdo corresponde a las anomalías calculadas utilizando el análisis operacional del ECMWF y reanálisis para una semana dada. Los otros paneles corresponden a las ocho predicciones mensuales empezando una semana aparte y verificando en esa semana. Las anomalías del ensemble son relativas al clima del ensemble, calculando a partir de las estadísticas. Aquellas áreas en las que la predicción del ensemble no es significativamente diferente de su climatología, de acuerdo con el test de WILCOXON-MANN-WHITNEY (WMW [87]), aparecen en blanco. El rango temporal de las predicciones es día 1-7, 5-11, 8-14, 12-18, 15-21, 19-25, 22-28 y 26-32. Esta figura da una idea de hasta qué punto las anomalías predichas verifican con el análisis del ECMWF e igualmente informan sobre la consistencia entre las predicciones mensuales de una semana a la siguiente (fuente: ECMWF) 


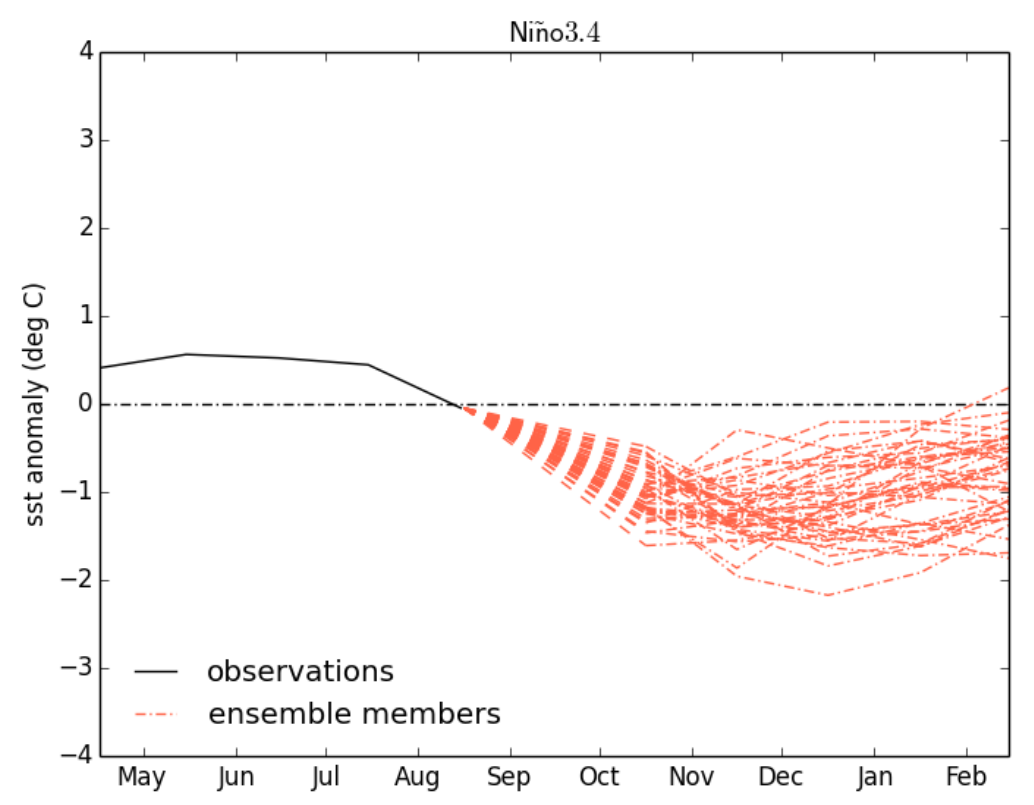

Figura 28.9: Penachos de anomalías medias mensuales (en rojo) de SST y anomalía de la temperatura observada para los seis meses precedentes (negro). Ver texto. Fuente: MetOffice.

Posteriormente los predictores de los grandes centros, analizan estos resultados a escala del país para elaborar el boletín de predicciones mensuales. Contrariamente, a las predicciones de escala de varios días, no se trata de informaciones detalladas y cifradas, sino de predicciones cualitativas que informan sobre la situación general esperada (perturbada, estable) y las grandes tendencias para la temperatura (superior o inferior a las normales) y las precipitaciones. Se presentan dos plazos:

- para la primera semana: el escenario más probable en términos de temperatura y precipitaciones en cada país

- para las dos semanas siguientes: la tendencia más probable únicamente para las temperaturas y solamente cuando un escenario dominante emerge de las simulaciones numéricas. La fiabilidad de las predicciones para las precipitaciones es insuficiente en este vencimiento.

La Figura 28.9 muestra otro ejemplo de producto, procedente en este caso de MetOffice. Para cada una de las distintas regiones del Pacífico tropical ecuatorial, en este caso la región Niño3.4, los gráficos de predicción (denominados penachos) muestran el promedio de las anomalías medias mensuales de las SST para cada miembro del ensemble (líneas rojas). La anoma- lía de la temperatura observada para los seis meses que preceden a la predicción se representa por una línea continua negra (fuente: MetOffice)

\subsection{Predicción estacional y anual}

A pesar de la naturaleza caótica de la atmósfera, la predicción estacional ha mostrado que es posible prever el estado medio de la atmósfera en los próximos tres a seis meses [61]. La predicción estacional se presenta bajo forma de predicciones cualitativas que informan sobre las grandes tendencias; es decir, si la próxima estación será más cálida o más fría, más seca o más húmeda que la normal, o próxima a la normal.

Como contraste con una simulación climática, una predicción estacional depende de manera crítica de una inicialización basada en la observación del sistema acoplado. Las predicciones resultantes intentan proporcionar información acerca de la evolución probable del sistema climático observado en las estaciones venideras. Sin embargo, conforme el rango de predicción aumenta, la importancia de las condiciones iniciales declina y los efectos del forzamiento externo empiezan a ser cada vez más importantes (Figura 28.10 en la página siguiente). 


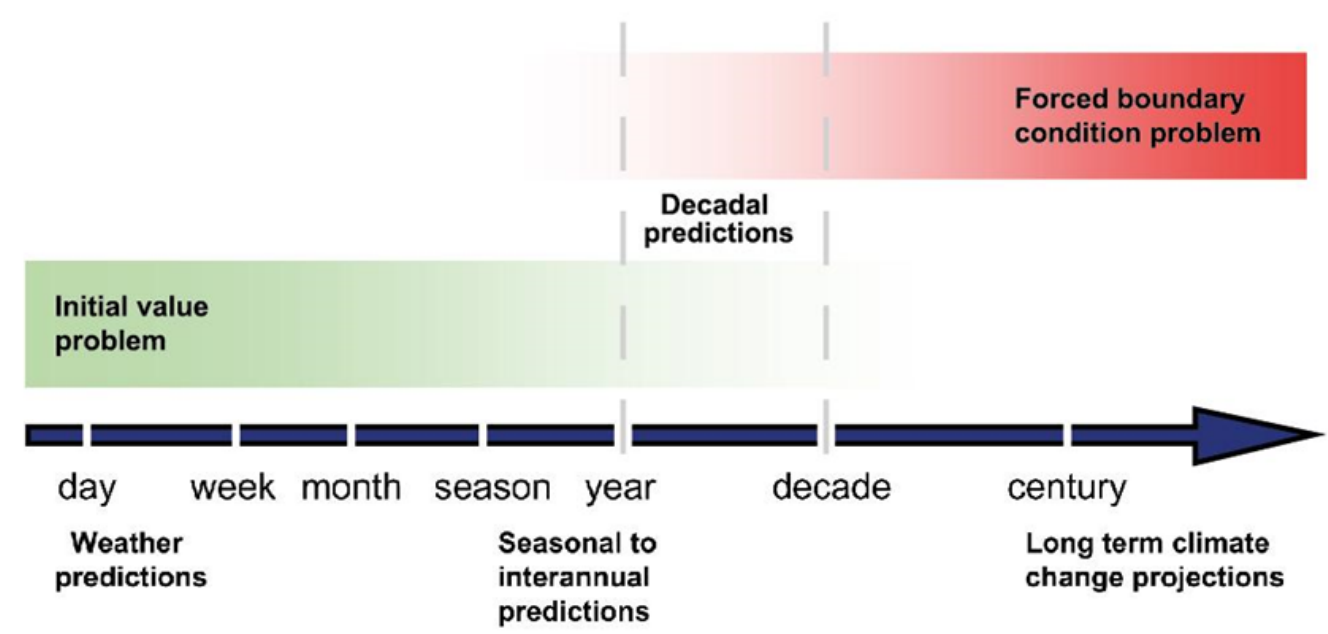

Figura 28.10: Importancia relativa de las condiciones iniciales y de contorno para las predicciones según las diferencias escalas temporales. (Fig. 1.2 de KIRTMAN et al. 2013 [43]).

La predecibilidad atmosférica estacional es mayor en ciertas regiones del globo y en ciertos periodos del año. En las regiones tropicales, la temperatura de superficie del océano pilota de forma intensa la circulación atmosférica mientras que la variabilidad natural del clima no es muy grande allí. La predecibilidad se acrecienta, por tanto, en esas regiones. En nuestras latitudes y en invierno, las teleconexiones con los trópicos son más fuertes que en verano, lo que aumenta la predecibilidad en el hemisferio norte y en Europa $[61,85]$.

La predicción estacional reposa en la modelización numérica del clima y en el acoplamiento entre sus diferentes actores. Es importante subrayar, que nos estamos refiriendo a una predicción de un estado medio (clima) y no de una cronología de estados instantáneos (tiempos). Se trata de una predicción de naturaleza probabilista, que puede ser útil en un contexto de gestión del riesgo climático, de toma de decisiones y de actividades sensibles a la meteorología (principalmente económicas). Tiene un valor añadido que es variable, en función de la zona, de la estación, del año y del parámetro. La predicción estacional representa pues la primera etapa de la adaptación a la variabilidad climática actual.

A pesar de su fiabilidad limitada en nuestras latitudes, este tipo de predicciones presentan un interés incuestionable para los responsables de las tomas de decisiones cuya actividad, muestre alguna dependencia de la meteorología (por ejemplo, energía, seguros, agricultura, hidrología). Siempre que se atisbe una tendencia, constituyen una información suplementaria con respecto a la climatología (el clima medio en un lugar y en un periodo dado). Asociados a otros da- tos, estas predicciones permitirán entonces anticipar y adoptar decisiones en plazos del orden de algunos meses.

Un aspecto interesante suscitado en relación con la fiabilidad fue la noción de ventanas de oportunidad en Europa. Este concepto relaciona el hecho, de que en determinadas épocas, ciertas influencias/ factores que confieren predecibilidad serán más intensos y/ o actuarán de manera conjunta. En tales situaciones, las señales en la predicción probablemente serán más intensas y la confianza en las predicciones climáticas puede ser mayor que lo que indicaría la habilidad promedio. Esas ventanas de oportunidad pueden favorecer el uso - de las predicciones climáticas para algunos usuarios dependiendo del fenómeno, umbrales y decisiones implicadas [69].

La dificultad de evaluar una predicción estacional ha retardado mucho tiempo el consenso sobre la validez de su enfoque científico. En la predicción a corto plazo, se puede evaluar al cabo de algunos meses la tasa de acierto y de fracaso de un sistema de predicción. En predicción estacional, habrá que esperar décadas para elaborar un juicio fiable. Por tanto, nos volvemos hacia el pasado, produciendo lo que se llama retropredicciones. Una retropredicción es una predicción producida retrospectivamente, años más tarde, pero sin hacer trampas, es decir, no utilizando ninguna información posterior al instante inicial de la predicción. Estas retropredicciones deben cubrir un periodo a la vez largo (por razones estadísticas) y reciente (por razones de homogeneidad del sistema de observación). Las aplicaciones operacionales hacen empezar este periodo en 1993 (comienzo de la observación altimétrica satelital), mientras que las evaluaciones en modo 
investigación comienzan en 1979 (inicio de la observación global de la temperatura del océano por los satélites).

El empleo de predicciones medias anuales todavía no está muy extendido, en parte debido a su relativa novedad, la falta de evaluaciones del nivel asociado de predecibilidad y la calidad de la predicción, y, por último, la escasez de aplicaciones. Sin embargo, las predicciones medias anuales se han utilizado hasta ahora para entender y predecir la causa de la variabilidad interanual dentro de la señal del cambio climático subyacente, permitiendo la monitorización a corto plazo del progreso de cambio climático. Así, si por ejemplo, se espera un año frío, debido por ejemplo a la influencia de un evento La Niña, consideraciones acerca de la variabilidad natural impuesta al calentamiento tendrían más peso en la predicción de la variabilidad media anual.

Aunque la calidad de la predicción media anual se reduce con respecto a las predicciones estacionales con alcances más cortos, existe un número sustancial de casos con habilidad positiva, lo que puede conducir al desarrollo de aplicaciones específicas de este tipo de predicción. Como en el caso de predicciones de la escala de tiempo estacional, el multimodelo muestra frecuentemente un mejor calidad de predicción que los otros experimentos mencionados en DoblasREYES ET AL. 2009 [19], aunque sea principalmente debido al mayor tamaño del ensemble.

\subsubsection{Particularidades del sistema de pre- dicción estacional del ECMWF}

El papel constituido por el océano y sus intercambios con la atmósfera son cruciales en esa escala temporal [48]. Las predicciones del sistema así constituido, contienen incertidumbres, principalmente asociadas al desconocimiento de las condiciones iniciales y de la física simplificada del modelo.

Para paliar el problema de incertidumbre de las condiciones iniciales, el modelo global se integra varias veces a partir de inicializaciones realistas, un poco diferentes unas de las otras. Se obtiene así un ensemble de predicciones que describe los futuros estados posibles, teniendo en cuenta una cierta incertidumbre de las condiciones iniciales. Para tener en cuenta la incertidumbre debida a la modelización, una solución consiste en recurrir a varios modelos globales, desembocando así en una predicción multimodelo. El valor de la predicción multimodelo se ha explorado en particular en los proyectos DEMETER (Development of a European Multi-model Ensemble System for Seasonal to Interannual Prediction [62]) y ENSEMBLES (Ensemble-based Predictions of Climate Changes and their Impacts [36, 75, 84]).

El ECMWF ha liderado las predicciones estacionales desde hace muchos años. La investigación en la predecibilidad de las escalas estacionales al comienzo de la década de 1990, condujo a la implementación del primer sistema de predicción estacional del ECMWF basado en un modelo acoplado océano-atmósfera en 1997. En noviembre de 2011, el último sistema de predicción estacional Sistema 4 entró en operación. Este Sistema de predicción estacional del ECMWF [71] será sustituido en breve por un sistema mejorado denominado SEAS5. Se espera que proporcione incluso predicciones estacionales de mayor calidad en los trópicos y predicciones estacionales de hielo marino. Otro avance importante es que se corresponde bien con el sistema de rango extendido del ECMWF. Esto marca un paso significativo en el camino hacia la predicción sin costuras a través de un rango completo de escalas temporales, desde el rango medio hacia las predicciones estacionales.

El 11 de julio de 2017 [12] entró en vigor una actualización sustancial. El nuevo ciclo incluye cambios en el modelo; en el número y uso de las observaciones; en la infraestructura del software; y en el procedimiento de asimilación utilizado para generar las condiciones iniciales de las predicciones. La actualización ha tenido un impacto positivo en la habilidad de la predicción en las predicciones de plazo medio y mensuales.

La estrategia de diez años adoptada por el ECMWF en 2016 incluyó dos objetivos científicos clave cara a conseguir la mejora de la habilidad de la predicción a plazo medio: una estimación más precisa del estado inicial, una representación coherente de la incertidumbre asociada con las observaciones y el modelo; y una mejor representación de los procesos físicos y químicos junto con las interacciones entre las diferentes componentes del sistema Tierra. Esto permite el uso de más observaciones y mejora su asimilación, incluyendo además cambios en los esquemas de radiación y convección junto con una nueva climatología de aerosoles, proporcionando, por tanto, una representación mejorada de los procesos del sistema Tierra. Ambos desarrollos han conducido a mejoras significativas en la habilidad de la predicción. 
Resulta importante tener en mente que los sistemas de predicción operacionales necesitan considerar cuestiones prácticas a la vez que la base científica de las predicciones y productos. La experiencia ha venido a demostrar que el control de calidad es una parte importante del Sistema multimodelo, ya que pueden presentarse una amplia variedad de problemas y errores.

Por otra parte, está el EUROSIP, un Sistema de predicción estacional multimodelo, consistente en un número de sistemas de predicción estacional acoplados independientemente, integrados en un marco de referencia común. Surgió a consecuencia de los resultados tan alentadores del Proyecto DEMETER y de otros proyectos, quienes establecieron los beneficios científicos conseguidos al combinar las predicciones de cinco modelos (francés, inglés, americano, japonés y el modelo del ECMWF). En 2015 se puso operativa la versión 5 del sistema de Météo-France que es bastante próxima a la versión del modelo del sistema Tierra que se utilizará para el próximo informe del IPCC (AR6). Cada dos o tres años se llevarán a cabo ciclos de mejora. Su establecimiento intensificará los esfuerzos sobre la evaluación de la predecibilidad decadal del clima, en colaboración con el Cerfacs (Centre Européen de Recherche et de formation avancée en calcul scientifique).

En un desarrollo separado, el Servicio de Cambio Climático de Copernicus (C3S) está probando un prototipo de servicio de predicción estacional que ofrecerá predicciones multimodelo de El Niño y que se espera que sustituya al sistema multimodelo EUROSIP en una fecha oportuna. Los suministradores principales son el ECMWF, la MetOffice y Météo-France. Además, el Centro Euro-Mediterráneo sobre Cambio Climático Italiano (CMCC) y el Servicio Meteorológico Nacional Alemán (DWD) empezarán a enviar datos para su incorporación en el paquete de productos del servicio durante 2017. Se juntarán con el NCEP y el JMA. Para más información, véase BROOKSHAW [9]. Los datos de todos los modelos participantes se archivan en el ECMWF, pudiéndose acceder a ellos mediante el acatamiento de los términos de la política de datos de EUROSIP.

\subsubsection{Productos (estacional)}

Las predicciones estacionales se elaboran esencialmente para ser difundidas hacia todos los usuarios potenciales bajo forma de mapas o boletines a través de la web (ECMWF). Las consecuencias de un suceso cálido en el Pacífico ecuatorial (El Niño) están suficientemente documentadas para que una predicción de la ocurrencia de este fenómeno sea interpretado en términos de sequías, riesgo de inundaciones, etc.

Existen, igualmente, aplicaciones de las predicciones estacionales desarrolladas para un uso preciso. Hay que destacar que, sobre todo en las regiones tropicales donde las puntuaciones son más elevadas, es donde existe una colaboración más estrecha entre los predictores y los usuarios, en general, mediante una adaptación estadística. Este tipo de enfoque requiere retropredicciones sobre plazos largos y cambios de versión poco frecuentes. Por eso, la gestión de una presa en el río Senegal incluye una componente de predicción estacional [2]. En América del Sur, se han realizado un cierto número de adaptaciones estadísticas por el consorcio Eurobrisa.

Los productos numéricos generados por el Sistema de predicción estacional del ECMWF [71] contienen información acerca de lo que cabría esperar en escalas de tiempo estacionales, pero no hay que olvidar que también contienen errores. No se recomienda un uso irreflexivo de los productos de predicción numéricos en bruto. Las predicciones tienen que prepararse cuidadosamente para los usuarios, tal vez combinando datos de varias fuentes empíricas y/o numéricas. La creación y la emisión de declaraciones de predicción preparadas de forma debida no es una misión del ECMWF, sino que es responsabilidad de los Servicios Meteorológicos Nacionales o las organizaciones internacionales responsables. Los mapas de probabilidad que aparecen en las páginas web están «sin calibrar», esto es, representan directamente las salidas del modelo, y no se ha aplicado ningún ajuste a las probabilidades para que tengan en cuenta los errores del modelo.

El ECMWF genera además un número de productos multimodelo que son creados a partir de la salida integrada de los modelos componentes del sistema EUROSIP. Su referencia oficial es productos EUROSIP. La mayoría de estos productos se proporcionan tan solo en formato gráfico, aunque también se encuentran disponibles algunos datos en formato numérico. $\mathrm{El}$ acceso a estos productos multimodelo es análogo al acceso de cualquier producto del ECMWF.

Los datos procedentes de los modelos individuales se archivan también en el ECMWF, pero en este caso, 
el acceso está sujeto a los términos especificados en la política de datos de EUROSIP (información más detallada en [81]).

En el Sistema multimodelo EUROSIP, las incertidumbres debidas a los errores de los modelos se encuentran mejor representadas, en consecuencia, la predicción EUROSIP es más fiable. Pueden encontrarse mejoras del sistema de predicción estacional y sus productos en las referencias $[1,58,76]$.

La variedad de los productos gráficos se diseña para mostrar perspectivas diferentes acerca del futuro predicho para el modelo. No existe ningún gráfico que pueda representar la cantidad ingente de información contenida en el ensemble de predicción.

Los productos de datos proporcionan acceso a valores de predicción cuantitativos y permiten la creación de un rango casi ilimitado de productos de predicción específicos de cada usuario. Mostraremos aquí unos pocos ejemplos.

Penachos. La Figura 28.11 muestra las regiones de El Niño donde se calculan los gráficos conocidos como penachos.

Las predicciones de las anomalías de la temperatura de la superficie del mar en el Pacífico Ecuatorial promediadas sobre las áreas arriba mencionadas se muestran en gráficas tanto anuales como estacionales (Figura 28.12).

Las anomalías medias mensuales predichas para cada miembro individual del ensemble se muestran como manchas rojas unidas por curvas rojas finas, y el análisis verificante, cuando se encuentra disponible se representa por una curva azul a trazos gruesos.

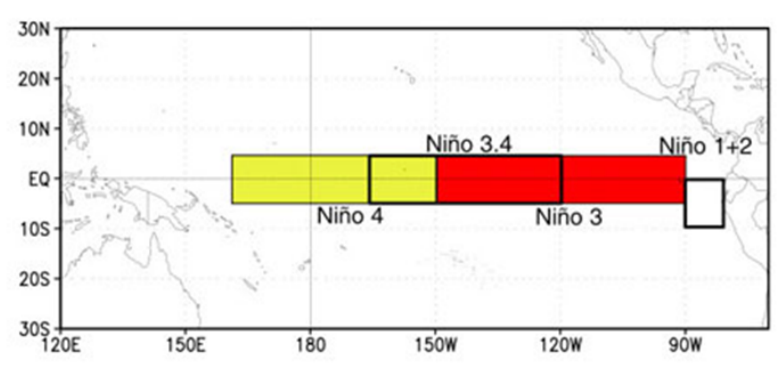

Figura 28.11: Regiones de El Niño en el Pacífico: Niño3, (5N-5S, 90-150W) Niño-3.4 (5N-5S, 120-170W) y Niño-4 (5N-5S, 160E-150W)

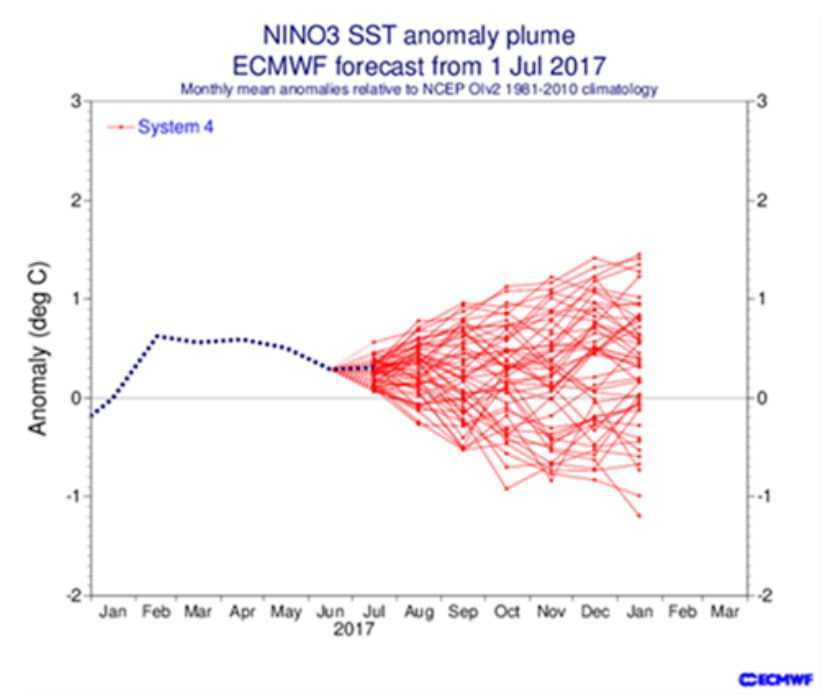

Figura 28.12: Penachos de las anomalías medias mensuales de SST para la región NINO3. Fuente: ECMWF.

Las predicciones empiezan el 1 de cada mes, y la anomalía media mensual para ese mes es el primer valor ploteado. Esto se junta con la anomalía media mensual procedente (observada) con una línea a trazos que representa la continuidad de la predicción con el análisis. Es importante notar que las líneas no representan la evolución continua de las SST sino que sencillamente conectan los valores mensuales.

Gráficas de verificación. Junto con los gráficos de penachos de El Niño, se muestran estadísticas de verificación basadas en las predicciones pasadas o retropredicciones [58]. EL sistema 4 tiene un balance dispersión-error mucho mejor que sistemas de predicción anteriores, particularmente en el Pacífico oriental (no mostrado). En el Niño4, sin embargo, los errores siguen siendo con frecuencia mucho mayores de lo que la anchura del penacho podría sugerir.

Mapas espaciales. Los mapas espaciales se producen mostrando las anomalías predichas por los modelos en cantidades promediadas estacionalmente. En la mayoría de los casos, se producen gráficos globales y regionales, aunque los globales y los de latitudes medias no se encuentran disponibles al público. Cada gráfico se etiqueta con el periodo de su validez, por ejemplo OND 2017 es el periodo trimestral octubre 2017-diciembre 2017. Se da la fecha de arranque de la predicción (p. ej. 01-09-2017 en la Figura 28.13 en la página siguiente) así como el número de integraciones del modelo en el ensemble de predicción y el número utilizado para definir el clima. 
ECMWF Seasonal Forecast

Prob(most likely category of $2 \mathrm{~m}$ temperature)

Forecast start reference is 01/09/17

Ensemble size $=51$, climate size $=450$
System 4

OND 2017

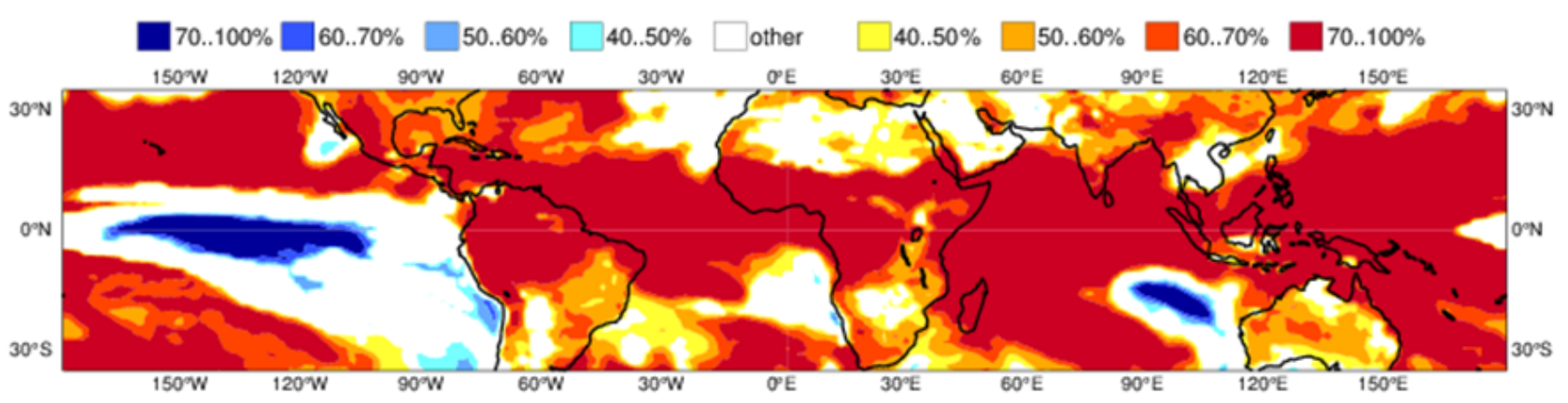

Figura 28.13: Los productos de datos proporcionan acceso a valores de predicción cuantitativos, y permiten la creación de un casi ilimitado rango de productos de predicción específicos de cada usuario. Los estados miembros del ECMWF tienen acceso a todos los datos directamente a través del sistema de archivo, y/o obtener datos de predicción atmosférica en tiempo real a través de la diseminación. Fuente: ECMWF.

Mapas de terciles. Cada mes, los especialistas en clima de los países que elaboran la predicción estacional examinan el sistema climático global (observaciones de los océanos, de la atmósfera y de los hielos marinos) y analizan los resultados de los diferentes modelos de predicción estacional (sistema EUROSIP y otros modelos). Establecen, en colaboración con investigadores especialistas en modelización y oceanógrafos, una síntesis de estas predicciones estacionales para el próximo trimestre. Esta síntesis es de gran ayuda en la elaboración del boletín disponible en la página web.

Puede suceder que las predicciones de dos modelos estén en desacuerdo. Así, existen en Europa (EUROSIP), en América del Norte (NMME) y en Asia (APCC)

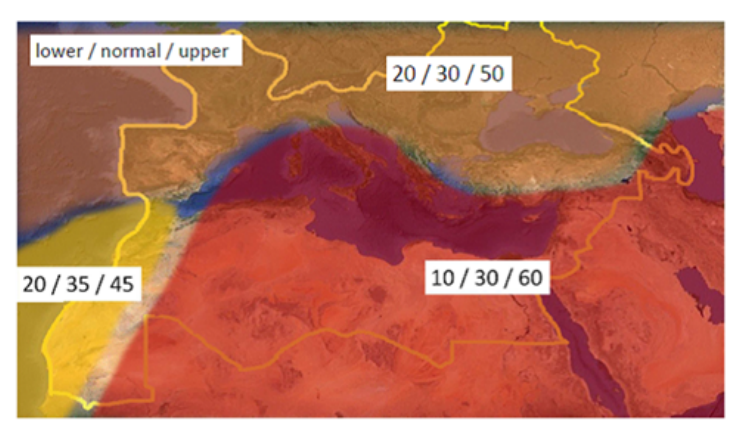

2017 SUMMER TEMPERATURE OUTLOOK consorcios que combinan las predicciones de varios modelos. Estas predicciones son accesibles gratuitamente bajo forma de mapas o boletines.

La predecibilidad estacional en la región mediterránea es muy pequeña excepto en las llamadas ventanas de oportunidad. Para solventar este problema, se recomienda el uso de todas las piezas de información posibles (modelos acoplados y algoritmos empíricos). Al manejar muchas fuentes de información, se impone la necesidad de integrarlas en un marco probabilista que combine de una manera óptima todas las fuentes de información; y, por último, las predicciones y verificaciones, ambas en una forma probabilista, tienen que asociarse a la toma de decisiones.

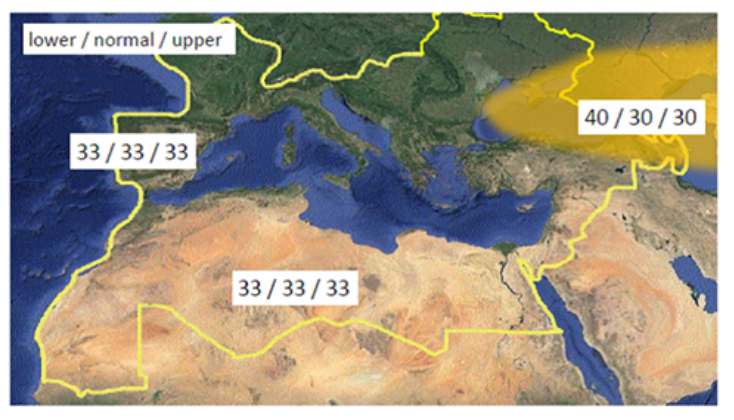

2017 SUMMER PRECIPITATION OUTLOOK

Figura 28.14: Predicción para el verano (JJA 2017) en el área de MedCOF de la temperatura (izquierda) y la precipitación (derecha). 
En el seno de MedCOF, el foro regional del clima para la región mediterránea (http://medcof . aemet.es, véase sec. 28.4 en la página siguiente para más deta1le), se emiten al año dos predicciones estacionales (para invierno y verano) para la precipitación y la temperatura, elaboradas por consenso. Se trata de una predicción basada en la salida de modelos dinámicos, modelos estadísticos y teleconexiones conocidas de las características climáticas a gran escala.

La Figura 28.14 en la página anterior muestra la predicción probabilista (por consenso) para las categorías en terciles de las anomalías para la temperatura media estacional (precipitación media estacional) y, similarmente, la precipitación, respecto al periodo 1981-2010. Debido a la tendencia de calentamiento del clima, las anomalías se encuentran afectadas por el periodo de referencia seleccionado.

Las temperaturas serán probablemente más cálidas de lo normal sobre la mayor parte del dominio de MedCOF (Figura 28.14 en la página anterior izquierda), siendo el tercil cálido más probable sobre la mayor parte de la región suroriental del dominio. La señal generalizada -relativamente cálida- es probable que lo sea parcialmente debido a la tendencia de calentamiento climático de fondo. Aunque las incertidumbres de la precipitación son mayores que para la temperatura, sobre la parte oriental del dominio se encuentra favorecido un fuerte y persistente verano, más seco de lo normal (principalmente procedente del modelo del ECMWF).

Para el resto de la región, no se aprecia en las pre- dicciones una señal a gran escala de precipitación (Figura 28.14 en la página anterior derecha). La predicción climatológica $(33,33,33)$ sobre la parte sur del dominio implica igualmente el hecho de que no se puede proporcionar una precipitación significativa para esas áreas en esta estación.

En AEMET existen actualmente varios sistemas de predicción estacional basados en modelos acoplados atmósfera-océano y en algoritmos empíricos. La predicción estacional operativa se realiza entre los días 25 y 30 de cada mes. Se realiza para los tres meses siguientes. Se trata de una predicción probabilista en forma de terciles. En particular, es una predicción por consenso obtenida analizando la información suministrada por todos los modelos disponibles. Se encuentra disponible en la web externa http://www. aemet.es/ es/serviciosclimaticos/prediccion_estacional

EUROSIP. Se observa (Figura 28.15) que la predicción estacional multimodelo EUROSIP del 1 de septiembre de 2016 (disponible a partir del 15 de septiembre) muestra alguna indicación de alta probabilidad de sequía en el oeste de Kenia y el sur de Etiopía pero no en Somalia, a pesar de existir una buena predicción de La Niña (https://wwa.climatecentral. org/analyses/somalia-drought-2016-2017).

IRI. Otro ejemplo de predicción estacional emitido por el Instituto de Investigación Internacional para la Predicción Climática (IRI) de EE. UU. en agosto de 2017, referida a la predicción de probabilidad multimodelo para la precipitación para el otoño (SON 2017) se muestra en la Figura 28.16 en la página siguiente.

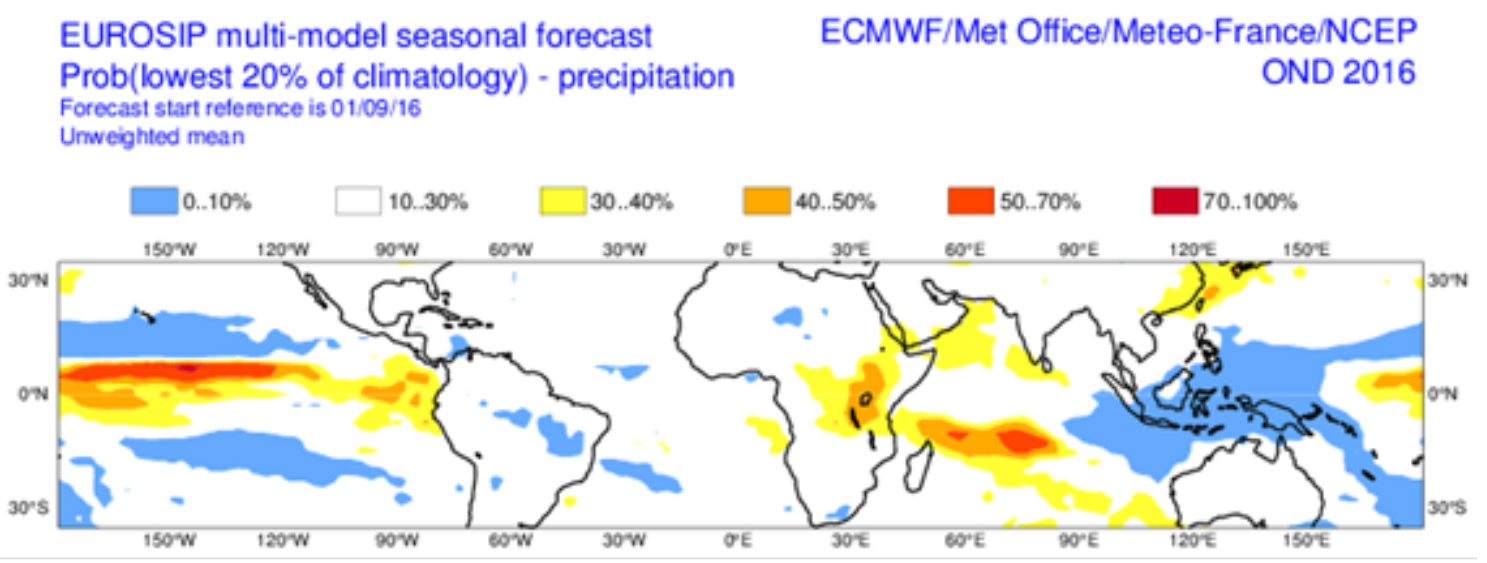

Figura 28.15: Predicción multimodelo EUROSIP para la probabilidad de la precipitación octubre-diciembre en el $20 \%$ más bajo de la distribución climatológica con el tiempo de referencia del análisis el 1 de septiembre de 2016 (disponible el 15 de septiembre de 2016). 
IRI Multi-Model Probability Forecast for Precipitation for September-October-November 2017, Issued August 2017

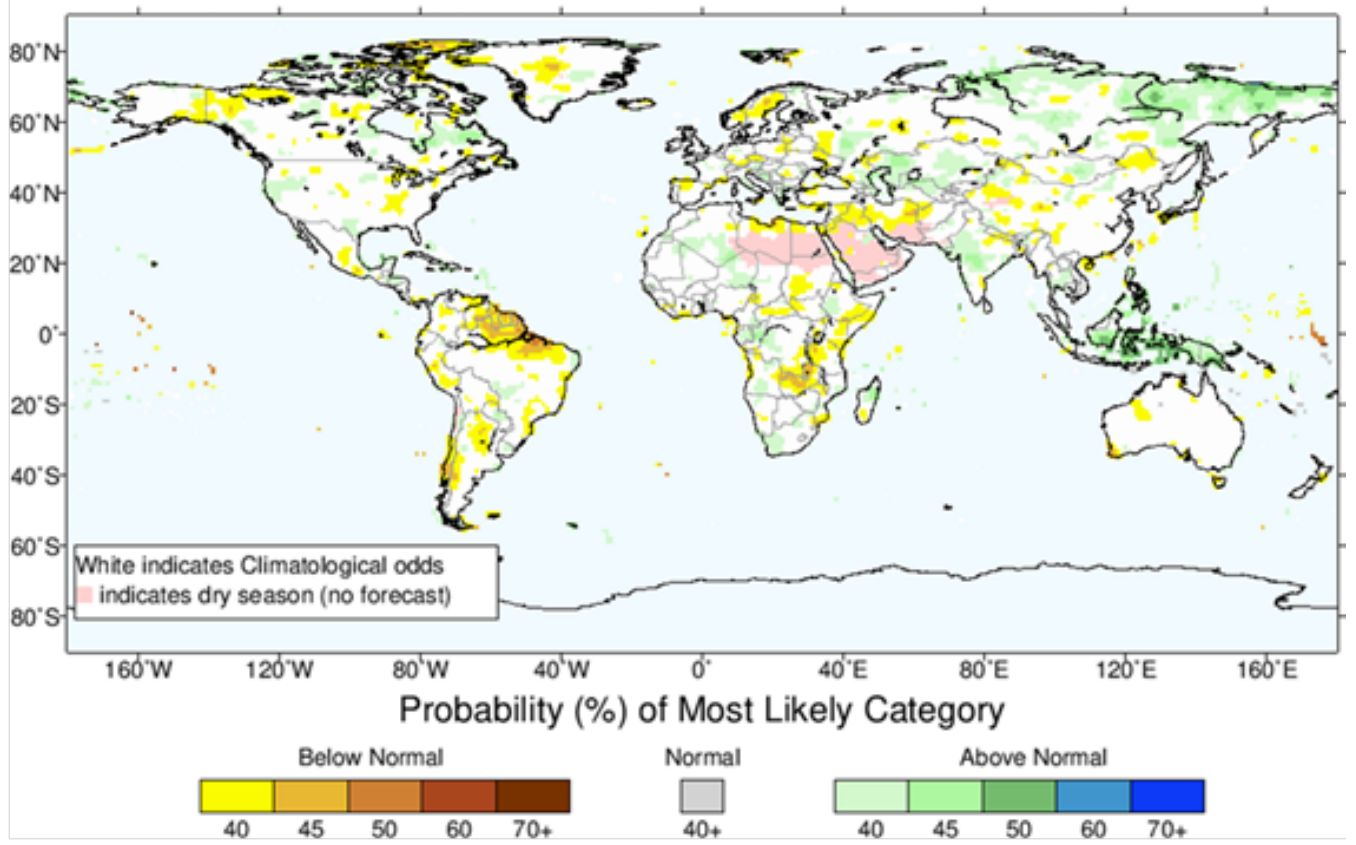

Figura 28.16: Probabilidades intensificadas de precipitación por debajo de lo normal para México y el sureste de EE. UU. desde octubre-diciembre hasta enero-marzo, y en parte del sureste de Sudamérica desde octubre-diciembre hasta diciembre-febrero. Se intensifican las probabilidades de predecir precipitación sobre lo normal en el norte de Sudamérica y la mayor parte de Indonesia y partes de Australia oriental desde octubre-diciembre hasta enero-marzo.

\subsubsection{Descripción del sistema ECMWF (predicción anual)}

Además de la predicción estacional que se hace cada mes, se elabora una predicción de rango anual o, simplemente, predicción anual cuatro veces al año, siendo las fechas de comienzo el 1 de febrero, 1 de mayo, 1 de agosto y 1 de noviembre. El rango de la predicción es 13 meses. Las predicciones de rango anual se corren como una extensión de la predicción estacional y se hacen utilizando el mismo modelo pero con un tamaño del ensemble más pequeño. Tanto las retropredicciones como las predicciones en tiempo real tienen un tamaño del ensemble de 15. Las predicciones de rango anual se diseñan principalmente para proporcionar una predicción para El Niño. En el momento actual, tienen un estatus experimental más que operacional.

\subsection{Centros especiales de predic- ción estacional}

Los sistemas de predicción estacional están operativos o casi operativos en un gran número de centros de pre- dicción alrededor del mundo [66, 71] y esto ha sido así en algunos casos desde el comienzo de la década de 1990.

La mayor parte de los grandes centros de predicción numérica realizan este tipo de predicción estacional: el ECMWF, servicios meteorológicos nacionales como Météo-France, UK MetOffice, los servicios japonés, coreano, chino, indio, canadiense, australiano, marroquí, y el NCEP americano. Igualmente, organismos de investigación producen también este tipo de predicciones como el Instituto Max-Planck en Alemania, el IRI en los Estados Unidos, o el CPTEC (centro de investigación de Brasil) e igualmente el centro australiano.

En el $16^{\circ}$ Congreso Meteorológico Mundial celebrado en 2011, la OMM adoptó una nueva iniciativa, consistente en desarrollar una Actualización Mundial del Clima Estacional (GSCU, de las siglas en inglés de Global Seasonal Climate Update, véase RoDRÍGUEZ, 2016 [64]). El objetivo del GSCU es el de asistir a los Servicios Meteorológicos e Hidrológicos Nacionales (SMHN), así como a los Centros Climáticos Regionales y a los Foros Regionales sobre Perspectivas del Clima. 


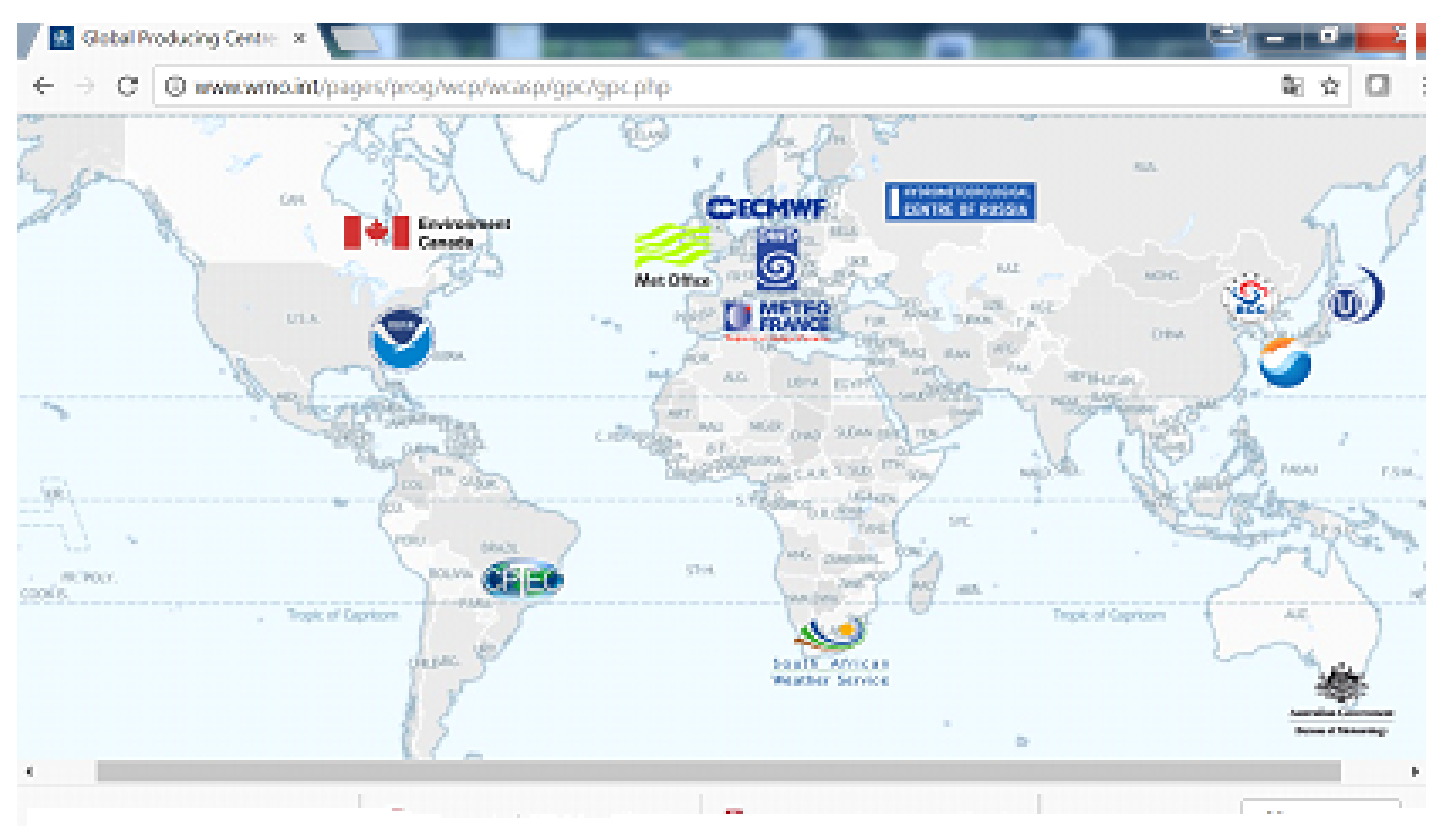

(A)

Figura 28.17: La OMM ha designado oficialmente los Centros globales de predicción y los siguientes centros líderes: WMO Lead Center for Long-Range Forecast Multi-Model Ensemble (LC-LRFMME) coordinados conjuntamente por KMA y CPC/NOAA. WMO Lead Center for Standard Verification System of Long-Range Forecasts (LC-SVSLRF) coordinados conjuntamente por BOM y MSC. (kolli-CSIS-2014_español)

Esta asistencia se realiza proporcionándoles evaluaciones del clima actual (vigilancia) y su predicción para la siguiente(s) estación(es) generadas por expertos desde una perspectiva global. Además, el GSCU proporciona información sobre la robustez y fiabilidad de las señales disponibles en las que se basa la predicción a escala estacional.

La iniciativa GSCU complementa la infraestructura básica de la OMM relacionada con la producción operativa de predicciones climáticas a escala estacional. Además de designar los 15 Centros Globales de Predicción (GPC, de las siglas en inglés de Global Production Centers), la OMM está creando Centros Regionales del Clima (RCC, de las siglas en inglés de Regional Climate Centres) para generar y suministrar datos y productos a mayor resolución y con un enfoque regional, así como para contribuir a la formación en la generación y uso de estos productos.

La OMM designó oficialmente 15 Centros Globales de Producción de predicciones a largo plazo como queda recogido en la Figura 28.17.

Los Centros Climáticos Regionales (RCC, de sus siglas en inglés) son centros de excelencia que crean productos climáticos regionales, entre ellos predicciones a escala estacional, en apoyo de las actividades climáticas a escalas regional y nacional. Los RCC están pensados y diseñados para fortalecer las capacidades de los miembros de la OMM en una determinada región y para ofrecer mejores servicios climáticos a los usuarios nacionales. Los servicios que prestan los RCC abarcan toda una serie de funciones obligatorias $\mathrm{y}$ adicionales altamente recomendadas, definidas $\mathrm{y}$ especificadas por la OMM. Los RCC pueden estructurarse de dos maneras: asumiendo en un centro único (multifuncional) todas las funciones de los RCC para la región correspondiente o distribuyéndose entre varios centros o nodos en una red de RCC. Este último es el caso de Europa en el que en una red de centros se distribuye responsabilidades temáticamente (ver Figura 28.18 en la página siguiente).

Los Foros Regionales de Perspectivas Climáticas (RCOF, de las siglas en inglés de Regional Climate Outlook Forum) comenzaron a funcionar en 1997 en Sudáfrica coincidiendo con un episodio récord de El Niño que atrajo la atención sobre los impactos de la variabilidad del clima y de las posibilidades del desarrollo de sistemas de predicción en escalas estacionales que ayudasen a la gestión de estos impactos. Existen tres componentes esenciales de los RCOF: producción operativa de las predicciones estacionales, fortalecimiento de las capacidades de los SNMH y la interacción con los usuarios. Ver Figura 28.19 en la página siguiente. 


\section{Situación actual sobre CRC de la OMM en el mundo}

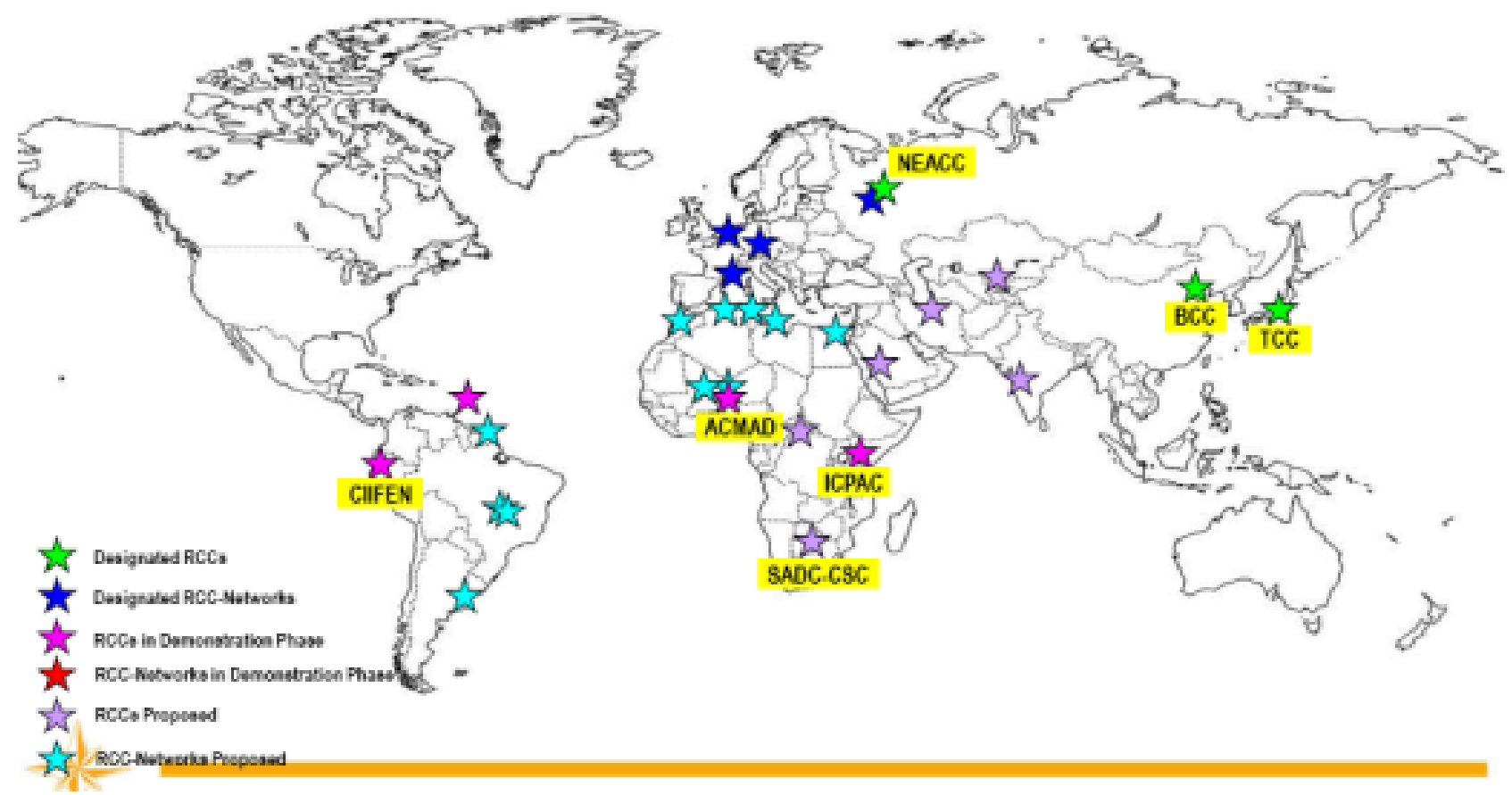

Figura 28.18: Véase http://www. wmo. int/pages/prog/wcp/wcasp/rcc/rcc. php.

\section{Foros Regionales del Clima alrededor del mundo}

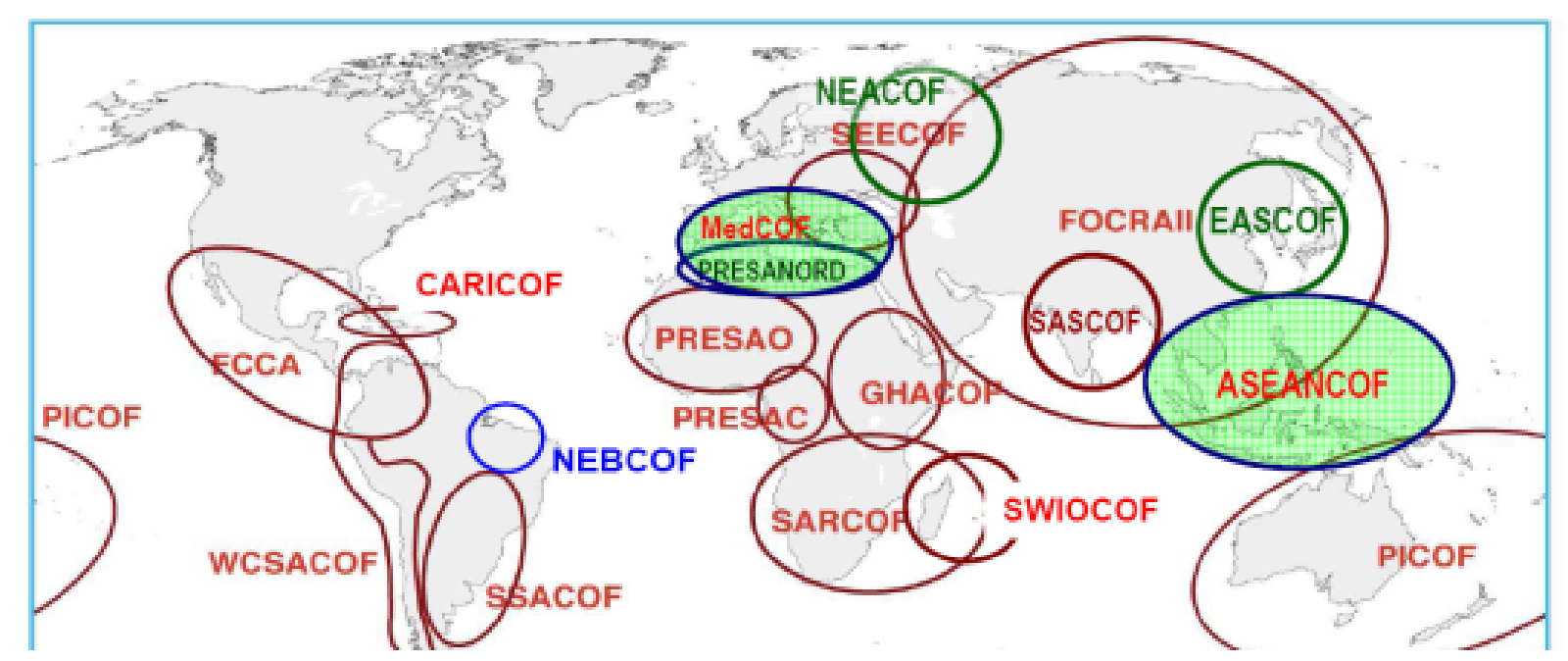

Figura 28.19: Foros regionales del clima alrededor del mundo (Regional Climate Outlook Forum RCOF, de sus siglas en inglés). 
Los RCOF reúnen a expertos en clima y predicciones climáticas para discutir y generar, mediante un procedimiento de consenso, predicciones climáticas con un alcance principalmente estacional. Al reunir a expertos de países que tienen características climatológicas comunes, los foros ayudan a garantizar la coherencia en el acceso e interpretación de la información climática. Un aspecto importante de los foros es la posibilidad de reunir a expertos en diversos campos, meteorólogos locales y usuarios finales de las previsiones en un entorno que fomenta la interacción y la formación. La Figura 28.19 en la página anterior muestra los foros actualmente funcionando bajo el paraguas de la OMM (información sobre RCOF disponible en la web de la OMM). En la RA VI de la OMM (Europa), el proceso de creación de los RCOF se lanzó en 2008 e inicialmente se crearon dos RCOF para la región europea: El South East European Climate Outlook (SEECOF) y el North-EurAsian COF (NEACOF). La sexagésima quinta sesión del Consejo Ejecutivo de la OMM apoyó el lanzamiento de un RCOF para la región mediterránea como una iniciativa conjunta de las regiones de Europa y África (RA VI y RA I, respectivamente). AEMET junto con la OMM -y tras conversaciones con muchas Partes- acordó la celebración de un «Scope meeting» en la sede central de AEMET, durante los días 12 a 14 de junio de 2013, para definir las características y objetivos de un futuro foro de predicción climática regional (RCOF), que recibió el nombre de MedCOF. La página web de MedCOF es (http://medcof . aemet.es). MedCOF abarca 34 países desde la región mediterránea, incluyendo los países balcánicos y caucásicos. La primera reunión se celebró en noviembre de 2013 y ha habido nueve ejercicios para producir las previsiones estacionales por consenso.

El IRI (International Research Institute for Climate and Society) de la Columbia University Se estableció merced a un acuerdo de cooperación entre el Programa climático de la NOAA y la Universidad de Columbia. Forma parte del Instituto de la Tierra (The Earth Institute) de la Universidad de Columbia y está ubicado en el Campus Lamont. El IRI alojó la primera Conferencia Internacional de Servicios Climáticos que se celebró en el Campus Morningside de la Universidad de Columbia en 2011. Esta conferencia lanzó la Alianza de Servicios Climáticos (Climate Services Partnership), cuya secretaria estuvo en el IRI hasta que se transfirió al Centro de Servicio Climático Alemán (German Climate Service Center) en Hamburgo en 2016.

Copernicus (http://copernicus.eu, mencionado también en la sec. 19.1 en la página 290) es un Progra- ma de la Unión Europea cuyo fin es el desarrollo de servicios de información europea basados en los satélites de Observación de la Tierra y datos in-situ (no espaciales). El programa está coordinado y dirigido por la Comisión Europea. Se implementó en asociación con los Estados Miembros, la Agencia Espacial Europea (ESA), la Organización Europea para la Explotación de los Satélites Meteorológicos (European Organisation for the Exploitation of Meteorological Satellites (EUMETSAT)), el ECMWF, Agencias de la Unión Europea y el Mercator Ocean.

\subsection{Predicción decadal}

La predicción decadal se clasifica entre la predicción estacional/interanual (unos cuantos meses-2 años), y las proyecciones de cambio climático que son más largas (50 o más años). En consecuencia, las predicciones decadales contribuyen a cerrar la brecha temporal entre las predicciones estacionales y las proyecciones de cambio climático, constituyendo un nuevo desafío en la comunidad dedicada al estudio del clima y del cambio climático. Doblas-Reyes (2009 [19]) señala que la predicción decadal intenta proporcionar información climática interanual útil maximizando la información de las observaciones, siendo un requisito primordial para ello la inicialización de los modelos acoplados océano-atmósfera.

Como describen de forma plástica y efectiva GODARD et al. (2012 [26]), la predicción decadal es la niña fascinante de la que todo el mundo habla. La predicción decadal puede avanzar, más rápido que su hermana mayor, la predicción estacional, porque cuenta con la ventaja de su experiencia. Tienen necesidades similares y participan en actividades similares y, por tanto, basándose en lo que pueden aprender una de la otra su maduración es, en cierta forma, un proceso de reforzamiento mutuo. Cualquier esfuerzo en inversión, ya sea en observaciones, modelización o investigación centradas en cualquiera de ambas escalas temporales beneficiará a ambas.

Por otra parte, las decisiones a las que afectan son de un tipo diferente. Las predicciones estacionales son más relevantes para las decisiones de gestión, mientras que las predicciones decadales pueden ser más útiles para las decisiones de planificación. Por tanto, ¿cómo es que dos escalas temporales tan diferentes podrían trabajar muy bien juntas en una perspectiva de investigación y de servicios climáticos? A pesar 
de sus diferencias obvias, existen elementos comunes, incluso complementarios. Donde la sinergia es mayor entre las predicciones estacionales y la investigación floreciente en las predicciones decadales es a través de su dependencia de los sistemas de predicción. Ambos sistemas de predicción utilizan el mismo tipo de modelos de circulación general, y hacen uso de los mismos sistemas de observación global. Más allá de estos elementos comunes de prioridad, sin embargo, existen un número de aspectos para los cuales, inversiones en el pasado, presente y futuro centrados en una única escala temporal podrían beneficiar a la otra escala.

La primera vez que se evaluó el potencial de las predicciones decadales fue en el AR5 del IPCC. Los retos de hacer predicciones fidedignas de las variaciones decadales requieren que los modelos sean capaces de distinguir entre las variaciones decadales no forzadas debidas a la dinámica interna del sistema climático acoplado y la componente externa forzada antropogénicamente, debida a cambios en los gases de efecto invernadero y condiciones de la superficie terrestre. Las variaciones decadales pueden ser causadas por cambios en la amplitud y frecuencia de los sucesos de El Niño, causados por cambios en las variaciones intraestacionales (MJO, etc., variaciones que pueden, a su vez, ser causadas por cambios en la convección tropical organizada. Por tanto, es importante que los modelos climáticos puedan resolver y simular los sistemas nubosos a meso-escala que organizan la convección profunda, las variaciones intra-estacionales, ENSO, así como el giro oceánico meridional decadal (MOC, de sus siglas en inglés).

Las predicciones decadales tienen un gran interés científico, interés que se traduce potencialmente en un beneficio para la sociedad. Muchas inversiones en infraestructura a gran escala se acometen en periodos que cubren varias décadas. Conociendo cómo el clima podría cambiar regionalmente durante este periodo, podría ayudar a mejorar los análisis costes-beneficios de las nuevas inversiones. El carácter probabilista de las predicciones resulta también potencialmente sobre el papel, útil en los análisis de riesgos. La predicción decadal es un nuevo campo que persigue proporcionar información climática interanual útil maximizando para ello, la información de las observaciones.

Finalmente, el desarrollo de modelos climáticos con mejor resolución horizontal y vertical debería constituir una prioridad para mejorar la representación de la variabilidad acoplada océano-atmósfera [28] y los efectos estratosféricos en las anomalías climáticas de la superficie y troposféricas [3, 38]. Las mejoras de los modelos y de los sistemas de asimilación no pueden desarrollarse sin una adecuada red de observación. El ENSO tiene una escala temporal de 3-7 años pero es únicamente predecible con una anticipación entre 6-12 meses, tal vez, como mucho, 18 meses para los sucesos muy intensos [16]. Este aspecto importante de las predicciones tiene que comunicarse a los usuarios considerando el uso de las predicciones decadales. Sin embargo, mientras que la variabilidad climática natural podría ser el motor dominante de las anomalías que varían con el tiempo más allá de una década para algunas regiones, la variabilidad natural del clima puede no ser predecible vía la inicialización; en contraste, la respuesta, que se desarrolla lentamente al cambio climático forzado, aunque de magnitud más pequeña en esa escala de tiempo, puede ser predecible, al menos en signo [37, 47]. Más allá de una década, la incertidumbre en la respuesta al forzamiento externo pasa a ser extraordinariamente importante como una fuente del error de predicción, mientras que la variabilidad decadal continúa como incertidumbre adicional significativa, especialmente en las escalas regionales [34].

\subsubsection{Descripción del sistema ECMWF (predicción decadal)}

Los conjuntos de predicciones decadales se llevan a cabo con el modelo acoplado del ECMWF. Las incertidumbres clave que dan origen al error de predicción en las predicciones de clima a corto plazo, son las incertidumbres en las condiciones iniciales, en la formulación del modelo y en el forzamiento radiativo futuro y pasado. Para representar la incertidumbre debida al modelo, se usan cuatro versiones diferentes del modelo acoplado del ECMWF [60]. Finalmente, la incertidumbre que surge de nuestro limitado conocimiento del forzamiento radiativo se tiene en cuenta incluyendo (o no) aerosoles troposféricos y/o estratosféricos asociados con los efectos de contaminación antropogénica y erupciones volcánicas. Cada experimento incluye como mínimo 3 y como máximo 7 miembros del conjunto generados por condiciones iniciales ligeramente diferentes. Las simulaciones tienen una duración de 10 años y se empezaron el 1 de noviembre, una vez cada cinco años en el periodo 1960 a 2005 [74]. El total de miembros del ensemble fueron 54, a partir de 10 experimentos de retropredicción y proporcionaron los valores para el «Ensemble 


\section{MultiModelo» del ECMWF.}

La habilidad en estas retropredicciones decadales procede fundamentalmente de dos fuentes: el forzamiento radiativo y la componente predictiva de la variabilidad climática natural. La componente principal del forzamiento radiativo consiste en la tendencia creciente de los gases de efecto invernadero bien mezclados [41]. Una comparación entre retropredicciones inicializadas y no inicializadas es el mejor camino para evaluar la importancia relativa de las condiciones iniciales con respecto al forzamiento. Sin embargo, cuando los experimentos compañeros no inicializados no se encuentran disponibles, la sustracción de la tendencia lineal de las anomalías constituye una buena aproximación para filtrar el efecto del calentamiento de los gases de efecto invernadero [27, 59].

El sistema es semejante al usado en predicción estacional, aunque con un mejor tratamiento de la concentración de gases de efecto invernadero y de los aerosoles de azufre (de sulfato de azufre). Las predicciones interanuales formuladas a partir del conjunto de simulaciones demuestran que el sistema tiene capacidad predictiva para la temperatura a escala global y regional con una antelación de varios años. Esto ocurre especialmente sobre los trópicos, donde la influencia de una buena predicción del contenido de calor influye directamente en la atmósfera.

La interpretación de las estimaciones del impacto positivo de las observaciones oceánicas sobre las predicciones tropicales y de ciertos aspectos del océano se ven limitadas por el pequeño tamaño de la muestra (que es típico de los experimentos previstos para el CMIP5, proyecto de intercomparación de modelos acoplados); la falta de observaciones fiables y el error sistemático.

El ECMWF también evalúa el sistema de predicción estacional acoplado atmósfera-océano utilizando las integraciones decadales. Varios ciclos IFS se han utilizado para evaluar el beneficio de las mejoras en la componente atmosférica. Conjuntos de ensembles de tres miembros de simulaciones de 10 años se han llevado a cabo utilizando el modelo acoplado IFS/HOPE [1]). Véase https://www.ecmwf.int/en/elibrary/ 14581-newsletter-no-138-winter-2013-14.

\subsubsection{Productos (decadal)}

En última instancia, la habilidad de los modelos de simulación basados en principios físicos se espera que sobrepase la de los modelos empíricos en un clima cambiante. La comparación directa proporcionará información acerca del progreso encaminado a la obtención de esa meta, que no se encuentra disponible en las intercomparaciones modelo-modelo.

Los modelos de simulación dinámica del Sistema climático de la Tierra de última generación se usan, con frecuencia, para hacer predicciones probabilistas sobre el clima futuro y fenómenos relacionados con la finalidad de proporcionar información útil para el apoyo a la toma de decisiones. La evaluación del comportamiento, la prestación de tales predicciones a partir de un modelo o conjunto de modelos es crucial no solo en términos del avance en el progreso científico, sino también en determinar cuánta información podrá hacerse disponible a los tomadores de decisiones a través de los servicios climáticos. Sería deseable establecer un enfoque transparente y robusto para la evaluación de la predicción, con el propósito de examinar hasta qué punto los mejores modelos disponibles en la actualidad son adecuados para las escalas temporales y espaciales de interés para llevar a cabo esta tarea. Una confirmación útil con la realidad vendría proporcionada comparando las simulaciones de los modelos no solo con otros modelos sino también con modelos empíricos que no incluyan una simulación física directa.

La evaluación y comparación de las previsiones decenales siempre se verán obstaculizadas por las muestras relativamente pequeñas que se presentan cuando se contrastan con el caso de las previsiones meteorológicas; El archivo de pronósticos-resultados decenales actualmente considerado es de sólo medio siglo de duración. Los avances tanto en la modelización como en la observación, así como los cambios en el clima de la Tierra, probablemente significarán que el archivo de pronóstico-resultado relevante seguirá siendo pequeño. Una mejora que podría hacerse para aclarar la habilidad de los modelos de simulación es mejorar el diseño experimental de las retropredicciones en particular, para aumentar el tamaño del conjunto utilizado. Para los modelos ENSEMBLES, cada conjunto de simulación consistió en sólo tres miembros lanzados a intervalos de 5 años. Los conjuntos más grandes y las fechas de lanzamiento más frecuentes pueden facilitar la evaluación de la habilidad sin esperar a que el archivo de pronósticos-resultados crezca. 


\subsection{Conclusiones}

Uno de los grandes desafíos lanzados por el desarrollo de los servicios climáticos es progresar en la predicción de las fluctuaciones climáticas en escalas espaciales relativamente finas y para horizontes temporales que van de la semana a la década. Estas fluctuaciones que se superponen a la tendencia de fondo del cambio climático antrópico, pueden destruir esta tendencia o por el contrario exacerbarla durante varios años. Su predicción requiere progresos importantes en la comprensión de la variabilidad natural del clima.

Los beneficios de la predicción estacional se establecen más fácilmente en las predicciones para algunas áreas de los trópicos. Esto es así porque en muchas áreas tropicales hay una cantidad moderada de señal predecible mientras que en las latitudes medias, las fluctuaciones aleatorias del tiempo son generalmente mayores que la componente predecible del tiempo. Hasta qué punto las predicciones estacionales se convierten en lo suficientemente buenas para ser útiles para un usuario particular, dependerá de los requerimientos del usuario. En algunos casos, los sistemas de hoy son ya útiles, aunque hay que ser extremadamente cuidadoso con interpretar apropiadamente las salidas de los modelos.

Conforme la fiabilidad continúe mejorando, un rango más amplio de aplicaciones será posible, y, por tanto, el valor de las predicciones estacionales se incrementará. Se necesita más trabajo, más investigación, para relacionar las probabilidades de los patrones de tiempo a gran escala con impactos detallados y aplicaciones. Hay que recordar, sin embargo, que existen límites rígidos acerca de lo que es físicamente posible conseguir con un sistema de predicción estacional: sólo será posible predecir un rango de resultados posibles. En muchos casos este rango podrá ser relativamente grande, y habrá un riesgo de que suceda algo inesperado. En muchas partes del mundo, mucha de la variabilidad en el tiempo permanecerá impredecible.

La investigación actual pretende la mejora de los sistemas de predicción decadal, e incrementar la comprensión de las razones para cualquier aparente habilidad. Mientras que los sistemas de predicción se espera que mejoren en las próximas décadas, la naturaleza caótica del sistema climático y el llamado efecto mariposa (sec. 5.5 en la página 64) impondrá límites inevitables en la habilidad predictiva. Adicionalmente, la brevedad del periodo con suficientes datos oceánicos para inicializar y evaluar las predicciones decenales presenta un reto mayor. Por último, hacer notar que los sistemas de predicción decadal se diseñan para explotar tanto las fuentes de predecibilidad, generadas internamente, como las forzadas externamente. Los científicos del clima distinguen entre predicciones decadales y proyecciones decadales. Las proyecciones explotan tan solo la capacidad predictiva procedente del forzamiento externo. Mientras los informes previos de evaluación del IPCC estuvieron centrados exclusivamente en proyecciones, el AR5 también evaluó la investigación de la predicción decadal y sus bases científicas.

La predicción decadal añade varios retos al diseño de los experimentos de ensemble y a su evaluación [20, 21, 24, 54, 59]; el análisis de los sistemas de predicción decadal han constituido un foco significativo del Quinto informe de evaluación del IPCC). Las predicciones decadales son de particular interés tanto para la información en los próximos 10 años como desde el punto de vista de la perspectiva de la evaluación de modelos climáticos. Sin embargo, no conviene olvidar que la predicción decadal, contrariamente a la predicción del tiempo y a la estacional a interanual, todavía está en su infancia.

La determinación del papel respectivo de las condiciones iniciales y de contorno para un plazo dado es esencial si se quiere concebir un sistema operacional de predicción climática. Por ejemplo, para un sistema de predicción a escala decadal, si la predecibilidad es un problema de primera especie (condiciones iniciales), resulta entonces crucial la puesta en marcha de un sistema continuo de observaciones rutinarias del océano que permitan generar un análisis detallado del estado oceánico que sirva para inicializar la predicción. Si, por el contrario, la presencia de errores mínimos en las condiciones iniciales oceánicas conducen a una saturación del error para escalas de tiempo «rápidas», es decir, inferiores a 10 años, se hace necesario entonces comprender mejor la respuesta del sistema climático a los cambios (relativamente predecibles) del forzamiento radiativo en las escalas multianuales (plurianuales) a decadales.

No resulta para nada superfluo subrayar el parentesco de las herramientas numéricas que se utilizan en los diferentes tipos de predicción: meteorológica, estacional y climática a largo plazo. Según el plazo contemplado, resulta necesario representar un mayor número de medios y considerar una gama más amplia de fenómenos físicos: la meteorología operativa con un vencimiento 
de unos cuantos días no tiene necesidad de una consideración detallada del océano, mientras que en su caso, la predicción climática estacional puede considerar la composición química de la atmósfera como constante. No queda más que todos estos modelos de predicción deban incluir una descripción numérica potente (efectiva) para la atmósfera si quieren representar el clima, a cualquier escala de tiempo. El hecho de que un número de modelos de predicción utilicen variantes de una misma modelización numérica de la atmósfera representa desde este punto de vista, una característica muy beneficiosa: la confrontación diaria del modelo atmosférico con la realidad meteorológica permite entonces mejorar las actuaciones y, quizás, más todavía, acrecentar la confianza que se puede poner en su calidad.

Para acabar, recordar que los ejes de mejora de la predicción del tiempo y del clima son: la calidad y la densidad de los sistemas de observación y de medida (en particular, los satélites), la optimización de los algoritmos y las prestaciones de los superordenadores $y$, por último, la mejora de los modelos y la comprensión de los fenómenos, en particular, la comprensión de las interacciones entre la atmósfera, el océano, los hielos y la biosfera.

Es importante subrayar igualmente que todavía queda mucho trabajo por hacer para mejorar el flujo de información desde la salida de los modelos numéricos hasta el usuario final, comunicando efectivamente, identificando claramente quiénes son los usuarios y qué es lo que quieren exactamente. La comunicación de la ciencia del clima no es una tarea fácil, hay que cuidar los canales de difusión y acudir quizás a los científicos sociales para que el mensaje llegue claro y los usuarios puedan incorporarlo a sus procesos de toma de decisión. 


\subsection{Referencias}

[1] Anderson, David y col. "Development of the ECMWF seasonal forecast System 3”. En: ECMWF Technical Memoranda 503 (2007) (citado en páginas 466, 474).

[2] Bader, Jean-Claude, Piedelievre, J P y LAMAGAT, Jean-Pierre. "Seasonal forecasting of the flood volume of the Senegal River, based on results of the ARPEGE Climate model". En: Hydrological Sciences Journal Journal Des Sciences Hydrologiques 51.3 (2006), páginas 406-417. ISSN: 0262-6667 (citado en página 465).

[3] Baldwin, Mark P y Dunkerton, Timothy J. "Stratospheric harbingers of anomalous weather regimes". En: Science 294.5542 (2001), páginas 581-584. DOI: 10 .1126/ science. 1063315 (citado en página 473).

[4] Berner, J. y col. "A Spectral Stochastic Kinetic Energy Backscatter Scheme and Its Impact on Flow-Dependent Predictability in the ECMWF Ensemble Prediction System”. En: Journal of the Atmospheric Sciences 66.3 (mar. de 2009), páginas 603-626. ISSN: 00224928. DOI: $10.1175 / 2008$ JAS2677 1 (citado en página 453$)$.

[5] Biodiversidad, Fundación y col. "Cambio Climático: Bases Físicas”. En: Guía Resumida del Quinto Informe de Evaluación del IPCC, Grupo de Trabajo I. Ministerio de Agricultura, Alimentación y Medio Ambiente, Madrid (2013), páginas 1-47 (citado en página 451).

[6] Boucher, Olivier y col. "Clouds and aerosols". En: Climate change 2013: the physical science basis. Contribution of Working Group I to the Fifth Assessment Report of the Intergovernmental Panel on Climate Change. Editado por STOCKER, Thomas F y col. Cambridge Univ. Press, Cambridge, UK, y New York, 2013, páginas 571-657 (citado en página 451).

[7] BRANDS, S y col. "Seasonal predictability of wintertime precipitation in Europe using the snow advance index". En: Journal of Cli- mate 25.12 (2012), páginas 4023-4028. DOI: 10.1175/JCLI-D-12-00083. 1 (citado en página 455).

[8] BRIER, Glenn W. "Verification of forecasts expressed in terms of probability". En: Monthly Weather Review 78.1 (1950), páginas 1-3. DOI: $10.1175 / 1520-0493$ (1950) 078<0001: VOFEIT>2 . 0. CO; 2 (citado en página 458).

[9] BROOKSHAw, A. "Seasonal forecasts from the Copernicus Climate Change Service". 2017. URL: http : / / medcof . aemet . es / images / doc _ events / medcof9 / docMedcof9 / presentaciones / C3Sseasonal _ for _ users_MedCOF_November2017.pdf (citado en página 465).

[10] Brown, Jaclyn N y Fedorov, Alexey V. "How much energy is transferred from the winds to the thermocline on ENSO time scales?" En: Journal of Climate 23.6 (2010), páginas 1563-1580 (citado en páginas 454, 456).

[11] Buizza, Roberto, Leutbecher, Martin y ISAKSEN, Lars. "Potential use of an ensemble of analyses in the ECMWF Ensemble Prediction System". En: Quarterly Journal of the Royal Meteorological Society 134.637 (2008), páginas 2051-2066. DOI: 10.1002/ qj . 346 (citado en página 453).

[12] BuizzA, R y col. "IFS Cycle 43r3 brings model and assimilation updates". En: ECMWF Newsletter 152.summer (2017). URL: https : / / www . ecmwf . int / en / elibrary/17439-newsletter-no-152summer-2017 (citado en página 464).

[13] Buontempo, Carlo y Hewitt, Chris. "EUPORIAS and the development of climate services". En: Climate Services (2017) (citado en página 454).

[14] Butler, Amy H y col. "The Climatesystem Historical Forecast Project: do stratosphere-resolving models make better seasonal climate predictions in boreal winter?" En: Quarterly Journal of the Royal Me- 
teorological Society 142.696 (2016), páginas 1413-1427. DOI: 10.1002 / qj . 2743 (citado en página 455).

[15] Cassou, Christophe. "La prévision décennale du climat". En: Le point sur 203.juin (2015), páginas 1-4. URL: https : / / www . actu-environnement. com/media/pdf / news - 24739 - prevision - decennale cgdd.pdf (citado en página 451).

[16] ChEN, Dake y col. "Predictability of El Niño over the past 148 years". En: Nature 428.6984 (2004), página 733. DOI: 10 . 1038/nature02439 (citado en página 473).

[17] Cohen, Judah y Jones, Justin. "A new index for more accurate winter predictions". En: Geophysical Research Letters 38.21 (2011). DOI: 10 . 1029/2011GL049626 (citado en página 455).

[18] CORTI, Susanna y col. "Reliability of decadal predictions". En: Geophysical Research Letters 39.21 (2012). DOI: 10.1029/ 2012GL053354 (citado en página 452).

[19] Doblas-Reyes, F J y col. "Addressing model uncertainty in seasonal and annual dynamical ensemble forecasts". En: Quarterly Journal of the Royal Meteorological Society 135.643 (2009), páginas 1538-1559. DOI: 10 . 1002 / qj . 464 (citado en páginas 464,472 ).

[20] Doblas-Reyes, F J y col. Decadal climate prediction with the ECMWF coupled forecast system: Impact of ocean observations. European Centre for Medium-Range Weather Forecasts, 2010. DOI: $10.1029 /$ 2010JD015394 (citado en páginas 452, 475).

[21] Doblas-Reyes, F J y col. "Forecast quality assessment of the ENSEMBLES seasonal-to-decadal Stream 2 hindcasts". En: ECMWF/TM 621 (2010), página 45 (citado en página 475 ).

[22] Du, H y col. "Sensitivity of decadal predictions to the initial atmospheric and oceanic perturbations". En: Climate dynamics
39.7-8 (2012), páginas 2013-2023. DOI: 10 . 1007 / s00382-011-1285-9 (citado en página 452).

[23] Ferranti, L y col. "Tropical-extratropical interaction associated with the 30-60 day oscillation and its impact on medium and extended range prediction". En: Journal of the Atmospheric Sciences 47.18 (1990), páginas 2177-2199. DOI: 10 . $1175 / 1520-$ 0469 (1990) 047<2177 : TEIAWT>2 . 0 . CO; 2 (citado en página 460).

[24] Fildes, Robert y Kourentzes, Nikolaos. "Validation and forecasting accuracy in models of climate change". En: International Journal of Forecasting 27.4 (2011), páginas 968-995. DOI: $10.1016 / \mathrm{j}$. i jforecast. 2011.03 .008 (citado en página 475).

[25] Flatau, Maria y col. "The feedback between equatorial convection and local radiative and evaporative processes: The implications for intraseasonal oscillations". En: Journal of the Atmospheric Sciences 54.19 (1997), páginas 2373-2386 (citado en página 460).

[26] GodDARD, Lisa y col. "Two time scales for the price of one (almost)". En: Bulletin of the American Meteorological Society 93.5 (2012), páginas 621-629. DOI: 10 . 1175 / BAMS - D - 11-00220 . 1 (citado en página 472).

[27] Guemas, V y col. "Identifying the causes of the poor decadal climate prediction skill over the North Pacific". En: Journal of Geophysical Research: Atmospheres 117.D20 (2012). DOI: 10 . 1029/2012JD018004 (citado en página 474).

[28] Guilyardi, Eric y col. "Representing El Nino in coupled ocean-atmosphere GCMs: the dominant role of the atmospheric component". En: Journal of Climate 17.24 (2004), páginas 4623-4629 (citado en página 473).

[29] Hagedorn, Renate y col. "Comparing TIGGE multimodel forecasts with reforecastcalibrated ECMWF ensemble forecasts". En: 
Quarterly Journal of the Royal Meteorological Society 138.668 (oct. de 2012), páginas 1814-1827. ISSN: 00359009. DOI: 10. 1002/qj . 1895 (citado en página 453).

[30] HAIDEN, Thomas y col. "Intercomparison of global model precipitation forecast skill in 2010/11 using the SEEPS score". En: Monthly Weather Review 140.8 (2012), páginas 2720-2733 (citado en página 453).

[31] HAIDEN, T y col. Evaluation of ECMWF forecasts, including 2014-2015 upgrades. European Centre for Medium-Range Weather Forecasts, 2015. URL: https : / / www . ecmwf . int / sites / default / files / elibrary / 2015 / 15275 - evaluation ecmwf - forecasts - including - 2014 2015 - upgrades . pdf (citado en página 461).

[32] Hanley, James A y MCNeil, Barbara J. "The meaning and use of the area under a receiver operating characteristic (ROC) curve." En: Radiology 143.1 (1982), páginas 29-36 (citado en páginas 457, 458).

[33] Haro, David y col. "Methodology for drought risk assessment in within-year regulated reservoir systems. Application to the Orbigo River system (Spain)". En: Water resources management 28.11 (2014), páginas 3801-3814. DOI: 10 . $1007 /$ s11269014-0710-3 (citado en página 457).

[34] Hawkins, Ed y Sutton, Rowan. "The potential to narrow uncertainty in regional climate predictions". En: Bulletin of the American Meteorological Society 90.8 (2009), páginas 1095-1107. DOI: 10.1175/ 2009BAMS2607. 1 (citado en página 473).

[35] Hewitt, Chris, Buontempo, Carlo y Newton, Paula. "Using climate predictions to better serve society's needs". En: Eos, Transactions American Geophysical Union 94.11 (2013), páginas 105-107. DOI: 10 . 1002/2013E0110002 (citado en página 454).

[36] Hewitt, Chris y Director, ENSEMBLES. "The ENSEMBLES project". En:
EGU Newslett 13 (2005), páginas 22-25 (citado en páginas 452,464$)$.

[37] Hurrell, J W y col. "Decadal climate prediction: opportunities and challenges". En: Community White Paper, OceanObs 9 (2009) (citado en página 473).

[38] InESON, S y ScAife, A A. "The role of the stratosphere in the European climate response to El Niño". En: Nature Geoscience 2.1 (2009), página 32. DOI: 10.1038/ngeo381 (citado en página 473).

[39] IS AKSEN, Lars y col. Ensemble of data assimilations at ECMWF. European Centre for Medium-Range Weather Forecasts, 2010 (citado en página 453).

[40] JАКов, C. y col. "The IFS cycle CY21r4 made operational in October 1999". En: Spring 87.87 (2000), páginas 2-9 (citado en página 453).

[41] Jansen, Eystein y col. "Paleoclimate". En: Climate change 2007: the physical science basis; contribution of Working Group I to the Fourth Assessment Report of the Intergovernmental Panel on Climate Change. Editado por Solomon, S y col. Cambridge Univ. Press, Cambridge, UK, y New York, 2007 (citado en páginas 452, 474).

[42] Jolliffe, Ian T. y Stephenson, David B. Forecast Verification: A Practitioner's Guide in Atmospheric Science. 2003, página 254. ISBN: 0470864419. DOI: 10.1016/ j. ijforecast. 2005.11.002 (citado en página 458).

[43] Kirtman, Ben y col. "Near-term climate change: projections and predictability". En: Climate Change 2013: The Physical Science Basis. Contribution of Working Group I to the Fifth Assessment Report of the Intergovernmental Panel on Climate Change, 1535 pp. Editado por STOCKER, Thomas F y col. Cambridge Univ. Press, Cambridge, UK, y New York, 2013 (citado en página 463). 
[44] KJELLSTRÖM, Erik y col. "Production and use of regional climate model projectionsA Swedish perspective on building climate services". En: Climate services 2 (2016), páginas 15-29. DOI: $10.1016 / \mathrm{j}$. cliser. 2016.06.004 (citado en página 450).

[45] Knutti, Reto, Masson, David y GettelMAN, Andrew. "Climate model genealogy: Generation CMIP5 and how we got there". En: Geophysical Research Letters 40.6 (2013), páginas 1194-1199. DOI: 10.1002/ grl. 50256 (citado en página 452).

[46] Kramer, Oliver. "K-nearest neighbors". En: Dimensionality Reduction with Unsupervised Nearest Neighbors. Springer, 2013, páginas 13-23. DOI: 10.1007/978-3-64238652-7_2 (citado en página 456).

[47] LEE, Cheng-Shang y col. "A climatology model for forecasting typhoon rainfall in Taiwan”. En: Natural Hazards 37.1-2 (2006), páginas 87-105. DOI: 10 . 1007 / s11069005-4658-8 (citado en página 473).

[48] LEROY, Anne y CÉron, Jean-Pierre. “Un défi de la prévision saisonnière: la descente d'échelle-La Nouvelle-Calédonie, un exemple à suivre". En: (2007) (citado en página 464).

[49] Leutbecher, Martin y col. "Ensemble forecasting". En: Journal of Computational Physics 227.7 (2008), páginas 3515-3539. ISSN: 00219991. DOI: 10 . $1016 / \mathrm{J}$. JCP . 2007.02.014 (citado en página 453).

[50] Longley, Paul A y col. "Geographical information systems. 2nd.” En: (1999) (citado en página 457 ).

[51] LORENZ, Edward N. "The predictability of a flow which possesses many scales of motion". En: Tellus 21.3 (jun. de 1969), páginas 289-307. ISSN: 00402826. DOI: 10 . 3402/tellusa.v21i3 . 10086 (citado en página 452).

[52] Madden, Roland A y Julian, Paul R. "Detection of a 40-50 day oscillation in the zonal wind in the tropical Pacific". En: Journal of the atmospheric sciences 28.5 (1971), páginas 702-708 (citado en página 459).

[53] Mason, Simon J. "On Using "Climatology" as a Reference Strategy in the Brier and Ranked Probability Skill Scores". En: Monthly Weather Review 132.7 (2004), páginas 1891-1895. ISSN: 0027-0644. DOI: $10.1175 / 1520-0493(2004) 132<1891$ : OUCAAR $>2$. 0 . CO ; 2 (citado en página 458).

[54] MeEHL, Gerald A y col. "Decadal prediction: can it be skillful?" En: Bulletin of the American Meteorological Society 90.10 (2009), páginas 1467-1485. DOI: 10.1175/ 2009BAMS2778 . 1 (citado en páginas 452, 475).

[55] Mitchell, Timothy D y Hulme, Mike. "Predicting regional climate change: living with uncertainty". En: Progress in Physical Geography 23.1 (1999), páginas 57-78 (citado en página 450).

[56] MochizUKI, Takashi y col. "Pacific decadal oscillation hindcasts relevant to near-term climate prediction". En: Proceedings of the National Academy of Sciences 107.5 (2010), páginas 1833-1837 (citado en página 452).

[57] Molteni, Franco y col. The new ECMWF seasonal forecast system (System 4). European Centre for Medium-Range Weather Forecasts, 2011 (citado en página 453).

[58] Molteni, F y col. "New web products for the ECMWF seasonal forecast System-3". En: ECMWF Newsletter No 111 (2007), páginas 28-33 (citado en página 466).

[59] Oldenborgh, Geert Jan van y col. "Decadal prediction skill in a multi-model ensemble". En: Climate dynamics 38.7-8 (2012), páginas 1263-1280. DOI: 10.1007/ s00382-012-1313-4 (citado en páginas $452,474,475)$.

[60] PALMER, T N y col. "Stochastic parametrization and model uncertainty". En: ECMWF Tech. Memo 598 (2009), páginas 1-42 (citado en páginas 453, 473). 
[61] Palmer, Tim N y Anderson, David L T. "The prospects for seasonal forecastingA review paper". En: Quarterly Journal of the Royal Meteorological Society 120.518 (1994), páginas 755-793. DOI: 10 .1002/qj . 49712051802 (citado en páginas 462, 463).

[62] Palmer, Tim N. y col. "Development of a European multimodel ensemble system for seasonal-to-interannual prediction (DEMETER)". En: Bulletin of the American Meteorological Society 85.6 (2004), páginas 853-872 (citado en páginas 452, 464).

[63] Power, Scott B y col. "Consensus on twenty-first-century rainfall projections in climate models more widespread than previously thought". En: Journal of Climate 25.11 (2012), páginas 3792-3809. DOI: 10. 1175 / JCLI - D-11-00354 . 1 (citado en página 452).

[64] Rodríguez-CAmino, Ernesto. "Predicción estacional operativa en el marco de la OMM". En: Tiempo y Clima 5.52 (2016) (citado en página 469).

[65] Rodriguez-Puebla, C y col. "Spatial and temporal patterns of annual precipitation variability over the Iberian Peninsula". En: International Journal of Climatology 18.3 (1998), páginas 299-316. DOI: 10. 1002/ (SICI) 1097-0088(19980315) 18: 3<299: : AID- JOC247>3 . 0 . CO ; 2-L (citado en página 454).

[66] SAHA, S y col. "The NCEP climate forecast system”. En: Journal of Climate 19.15 (2006), páginas 3483-3517 (citado en página 469).

[67] ShutTs, Glenn. "A kinetic energy backscatter algorithm for use in ensemble prediction systems". En: Quarterly Journal of the Royal Meteorological Society 131.612 (2005), páginas 3079-3102. DOI: 10.1256/qj .04.106 (citado en página 453).

[68] Slingo, Julia y Palmer, Tim. "Uncertainty in weather and climate prediction". En: Phil. Trans. R. Soc. A 369.1956 (2011), páginas 4751-4767. DOI: 10 . 1098/rsta . 2011.0161 (citado en páginas 448, 449).

[69] SoAres, Marta Bruno y Dessai, Suraje. "Exploring the use of seasonal climate forecasts in Europe through expert elicitation". En: Climate Risk Management 10 (2015), páginas 8-16 (citado en página 463).

[70] Stan, Cristiana y Kirtman, Ben P. "The influence of atmospheric noise and uncertainty in ocean initial conditions on the limit of predictability in a coupled GCM". En: Journal of Climate 21.14 (2008), páginas 3487-3503 (citado en página 452).

[71] Stockdale, T, Balmaseda, M y FeRRANTI, L. "The 2015-2016 El Niño and beyond". En: ECMWF Newsletter 151.spring (2017). URL: https: //www . ecmwf . int/ en/elibrary/17181-newsletter-no151-spring-2017 (citado en páginas 464, 465, 469).

[72] Stockdale, Timothy N y col. "Ocean modeling for ENSO". En: Journal of Geophysical Research: Oceans 103.C7 (1998), páginas 14325-14355. DOI: 10 . 1029 / $97 \mathrm{JC0} 2440$ (citado en página 452).

[73] Stocker, Thomas F y col. Climate Change 2013: The Physical Science Basis. Contribution of Working Group I to the Fifth Assessment Report of the Intergovernmental Panel on Climate Change, 1535 pp. 2013 (citado en página 452).

[74] Taylor, Karl E, Stouffer, Ronald J y MeEhl, Gerald A. "An overview of CMIP5 and the experiment design". En: $\mathrm{Bu}$ lletin of the American Meteorological Society 93.4 (2012), páginas 485-498 (citado en página 473$)$.

[75] VAn DER Linden, Paul y Mitchell JFB, Editors. "ENSEMBLES: Climate change and its impacts-Summary of research and results from the ENSEMBLES project". En: Geophysical Research Letters (2009) (citado en páginas 452, 464). 
[76] Vitart, F, Stockdale, $T$ y FerranTI, L. "Seasonal forecasting of tropical storm frequency". En: ECMWF Newsletter 112 (2007), páginas 16-22 (citado en página 466).

[77] Vitart, Frédéric. "Evolution of ECMWF sub-seasonal forecast skill scores". En: Quarterly Journal of the Royal Meteorological Society 140.683 (2014), páginas 1889-1899. DOI: $10.1002 /$ qj . 2256 (citado en páginas 453,460$)$.

[78] Voces AвоY, José y col. "Sistema estadístico de predicción estacional para la gestión de los embalses en España". En: Nota Técnica 21 (2016). URL: http: //www . aemet. es / es / conocermas / recursos _ en _ linea/publicaciones_y_estudios / publicaciones / detalles / NT _ 21 _ AEMET (citado en páginas 454-456, 458).

[79] VVAA. Predicción estacional para la gestión de embalses. 2016. URL: https : / / www . miteco - gob . es / es / agua / temas/evaluacion-de-los-recursoshidricos / Prediccion - estacional gestion - embalses . aspx (visitado 09-04-2018) (citado en página 457).

[80] VVAA. Set VI - Atmospheric Model Ensemble extended forecast (ENS extended) - ECMWF. 2017. URL: https : / / www . ecmwf . int/en/forecasts / datasets / set-vi (visitado 09-04-2018) (citado en página 461).

[81] VVAA. The EUROSIP multi-model seasonal forecasting system I ECMWF. 2017. URL: https : / / www . ecmwf . int / en / forecasts / documentation - and support / long - range / seasonal forecast - documentation / eurosip user - guide / multi - model (visitado 09-04-2018) (citado en página 466).
[82] WALKer, Gilbert T. "Correlations in seasonal variations of weather. I. A further study of world weather". En: Mem. Indian Meteorol. Dep. 24 (1924), páginas 275-332 (citado en página 454$)$.

[83] WeISHEIMER, Antje y col. "On the predictability of the extreme summer 2003 over Europe”. En: Geophysical Research Letters 38.5 (2011). DOI: 10 . 1029/2010GL046455 (citado en página 452 ).

[84] WeISHEIMER, A y col. "ENSEMBLES: A new multi-model ensemble for seasonalto-annual predictions - Skill and progress beyond DEMETER in forecasting tropical Pacific SSTs". En: Geophysical research letters 36.21 (2009). DOI: 10 . 1029 / 2009GL040896 (citado en páginas 452, 464).

[85] WILBY, Robert. "Evidence of ENSO in the synoptic climate of the British Isles since 1880". En: Weather 48.8 (1993), páginas 234-239. DOI: $10.1002 / \mathrm{j}$. 1477-8696. 1993. tb05897 . x (citado en página 463).

[86] Wilby, Robert L y Dessai, Suraje. "Robust adaptation to climate change". En: Weather 65.7 (2010), páginas 180-185. DOI: 10 . 1002/wea. 543 (citado en página 450).

[87] WILKS, Daniel S. Statistical Methods in the Atmospheric Sciences. Academic Press, 2011, página 676. ISBN: 9780123850225. URL: https : / / www . sciencedirect . com / bookseries / international geophysics / vol / 100 (citado en páginas 458, 461).

[88] ZhanG, S y col. "System design and evaluation of coupled ensemble data assimilation for global oceanic climate studies". En: Monthly Weather Review 135.10 (2007), páginas 3541-3564 (citado en página 452). 